\title{
The University of Colorado Meaning Norms
}

\author{
CAROL A. NICKERSON and DESMOND S. CARTWRIGHT \\ University of Colorado, Boulder, Colorado
}

\begin{abstract}
There exist surprisingly few normative lists of word meanings even though homographs-words having single spellings but two or more distinct meanings-are useful in studying memory and language. The meaning norms that are available all have one or more weaknesses, including: (1) the collection of free associates rather than meanings as responses to the stimulus words; (2) the collection of single rather than multiple responses to the stimulus words; (3) the inclusion of only the two most frequently occurring meaning categories, rather than all meaning categories, for the stimulus words; (4) omission of the responses typical of each meaning category; (5) inadequate randomization of the presentation order of the stimulus words; and (6) unpaced presentation of the stimulus words. We have compiled meaning norms for 90 common English words of low, medium, and high concreteness using a methodology designed to correct these weaknesses. Analysis showed that words of medium concreteness have significantly more firstresponse meanings than do words of either low or high concreteness, lending support to the view that concreteness is a categorical, rather than a continuous, semantic attribute.
\end{abstract}

Researchers who study verbal behaviors need information about the semantic characteristics of English words in order to create, calibrate, or select appropriate verbal materials for their experiments. This need has led to the publication of a wide variety of normative word lists. These lists consist of collections of words accompanied by normative data about such semantic attributes as concreteness (Friendly, Franklin, Hoffman, \& Rubin, 1982; Gilhooly \& Hay, 1977; Gilhooly \& Logie, 1980a, 1980b; Gorman, 1961; Paivio, Yuille, \& Madigan, 1968; Spreen \& Shultz, 1966; Toglia, Battig, Barrow, Cartwright, Posnansky, Pellegrino, Moore, \& Camilli, 1978), imagery and imageability (Friendly et al., 1982; Gilhooly \& Hay, 1977; Gilhooly \& Logie, 1980a, 1980b; Paivio et al., 1968; Stratton, Jacobus, \& Brinley, 1975; Toglia et al., 1978; Walker, 1970), meaningfulness (Gilhooly \& Hay, 1977; Locascio \& Ley, 1972; Noble, 1952; Paivio et al., 1968; Spreen \& Shultz, 1966; Stratton et al., 1975; Toglia et al., 1978), frequency (Carroll, Davies, \& Richman, 1971; Kucera \& Francis, 1967; Thorndike \& Lorge, 1944), categorizability and categorization (Battig \& Montague, 1969; Cohen, Bousfield, \& Whitmarsh, 1957; Posnansky, 1978; Shapiro \& Palermo, 1970; Toglia et al., 1978; Uyeda \& Mandler, 1980), familiarity (Gilhooly \& Hay, 1977; Gilhooly \& Logie, 1980a, 1980b; Stratton et al., 1975; Toglia et al., 1978), number of features (Toglia et al., 1978), pleasantness (Toglia et al.,

We gratefully acknowledge the assistance of Perle Bochert, Annette Laverty, Linda Liebelt, Sandy Loringer, Ruth McHugh, Andrea Stock, Robbie Toney, and two anonymous reviewers. This paper is a revised version of a technical report prepared for the Institute for the Study of Intellectual Behavior at the University of Colorado (Nickerson \& Cartwright, 1979). A summary of this report appeared in Cartwright \& Nickerson (1979). Requests for reprints of any of these papers should be sent to Desmond S. Cartwright, Muenzinger Psychology Building, University of Colorado, Boulder, CO 80309-0345.
1978), pronunciability (Ley \& Karker, 1974; Spreen \& Shultz, 1966), and associates (Battig, 1964; Palermo \& Jenkins, 1964; Postman \& Keppel, 1970).

However, there are surprisingly few normative lists of word meanings available, even though homographswords having single spellings but two or more distinct meanings-make excellent stimuli for the study of encoding specificity (e.g., Goldstein, Schmitt, \& Scheirer, 1978; Light \& Carter-Sobell, 1970; Winograd \& Conn, 1971), recall and recognition memory (e.g., Kausler \& Kamichoff, 1970; Rowe, 1973), set or priming (e.g., Cramer, 1968; Nelson, Walling, \& McEvoy, 1979; Schvaneveldt \& Meyer, 1973; Skanes \& Donderi, 1973), transfer (e.g., Hashtroudi \& Johnson, 1976; Mueller, Brown, \& Kausler, 1975), imagery (e.g., Begg \& Clark, 1975), cerebral laterality (e.g., Wollen, Cox, Coahran, \& Shea, 1979), and even the relationship between psychopathology and verbal behavior (e.g., Benjamin \& Watt, 1969).

The lack of word-meaning norms is probably due to the fact that most researchers rely on dictionaries and thesauri when information is needed about this particular semantic attribute. This solution is unlikely to be satisfactory for two reasons. First, dictionary and thesaurus searches are extremely laborious and time consuming. Second, although these sources certainly list the possible meanings of any given word, they give no indication of the relative frequencies of those meanings. The meanings in most dictionaries and thesauri are not usually arranged in order of frequency of occurrence, as is commonly supposed, so that one cannot assume even a rank ordering of meanings. In many experimental studies, however, information about meaning frequency is essential. For example, it is well known that the particular meaning attributed to a homograph is heavily dependent upon the context in which the homograph appears. For experiments 
judging the effects of context variation on verbal meaning, it is important for comparison purposes to know how often various meanings would be assigned to words without context (i.e., in the normative situation) (Cramer, 1970).

Unfortunately, the six meaning-norms word lists that are available (Cramer, 1970; Geis \& Winograd, 1974; Kausler \& Kollasch, 1970; Nelson, McEvoy, Walling, \& Wheeler, 1980; Perfetti, Lindsey, \& Garson, 1971; Wollen, Cox, Coahran, Shea, \& Kirby, 1980) all have weaknesses. One problem centers on the methodology used to obtain meanings. In none of the six studies were subjects instructed to provide meanings for the stimulus words. Instead, in all the studies but that of Wollen et al. (1980), subjects were instructed to respond to each stimulus word with a free associate. For example, Perfetti et al. (1971) instructed their subjects to respond with "the first word that came to mind"' (p. 1) upon hearing the stimulus word, and Nelson et al. (1980) asked their subjects to "write next to each word the first word that it makes you think of' (p. 16). The associates for each word were then assigned to meaning or sense categories by having two to five judges determine the meaning of the word most likely to produce each associate. Wollen et al. (1980) noted that this "semantic scoring" of free associates is a problematic technique for the determination of meaning because it is sometimes impossible to tell from the associate which meaning a subject encoded for the stimulus word. They attempted to circumvent this problem by instructing their subjects to use each stimulus word in a short phrase or sentence rather than to give a free associate to the word.

Why the compilers of meaning norms have not asked their subjects to provide a meaning rather than a free associate for each stimulus word is unclear. Comments by Perfetti et al. (1971) that "no mention was made [to subjects] of multiple meanings" (p. 1) and by Nelson et al. (1980) that "the instructions never mentioned the homographic nature of the stimuli" (p. 16) imply that free associates rather than meanings were collected in order to keep subjects blind as to the purpose of the studies. However, what the detrimental effect of asking subjects to respond to a stimulus word with a meaning rather than with a free associate would be is not evident. Furthermore, collecting meanings directly would have the advantage of lightening the onerous task of semantic scoring of word associates by multiple judges and should reduce the number of ambiguous responses to the stimulus words.

A second problem is that the methodology used in all six of the meaning-norms studies required only a single response to each stimulus word. Meaning norms based on single (that is, first) responses may be adequate for some experimental purposes, but a more useful and complete set of norms could be developed by requiring multiple responses to each stimulus word and then tabulating the response frequency of each meaning category of a stimulus word both for the first response and for all responses to that stimulus word.
A third problem is that not all of the studies list all of the meaning or sense categories of the stimulus words. The lists compiled by Kausler and Kollasch (1970) and Geis and Winograd (1974) report the frequencies of occurrence of only the two most commonly occurring meanings of the stimulus words, even though the data clearly indicate that a number of these words may have many more than two meanings. Some meanings are omitted, and others are combined; for example, Kausler and Kollasch (1970) combined the meanings of "just" and "beautiful" for the stimulus word FAIR.

A fourth and related problem is that some of the studies do not list, in addition to the meaning or sense categories of each stimulus word, the free associates assigned to each such category. Geis and Winograd (1974) list only the meaning categories, and Wollen et al. (1980) list only phrase exemplars of meaning categories. Kausler and Kollasch (1970) list only the two primary associates for each meaning category. Cramer (1970), Perfetti et al. (1971), and Nelson et al. (1980) do provide complete lists of associates accompanied by the frequencies or percentages of occurrence of those associates for each meaning category, so that it would be possible for a researcher to recombine associates into different meaning categories if he or she so desired.

A fifth problem concerns the presentation order of the stimulus words. Because the encoded meaning of a polysemous word is context dependent, it can be influenced by the previous word or words presented. Although they admit this dependency, the compilers of the meaning norms have not exercised much control over presentation order. Perfetti et al. (1971) used only two different word orders, one of which was the reverse of the other, and did not state whether the order of the words was randomized. Kausler and Kollasch (1970) used two different random orders, and Geis and Winograd (1974) used four. Cramer (1970) randomized the order of the stimulus words and presented 20 words on each of five pages of a test booklet. The five pages appeared in all possible orders; however, the words on any given page were always in the same order. Nelson et al. (1980) adopted a similar procedure, randomizing the order of eight pages of 40 words each, with the words on any given page apparently always appearing in the same random order. Wollen et al. (1980) noted the problem and attempted to exert a greater degree of control over the stimulus word presentation than had previous researchers by employing six different random orders and counterbalancing the pages on which the stimulus words appeared. No study has exerted maximum control by presenting the words to each subject in a different random order.

In criticizing the unpaced stimulus-word presentations of the Cramer (1970), Kausler and Kollasch (1970), and Geis and Winograd (1974) studies, Wollen et al. (1980) recognized a sixth problem of the previously compiled meaning norms. They noted that, in their experience, subjects in unpaced studies take much care in responding to the initial stimulus words but tend to rush as they near 
the end of the stimulus word list. Accordingly, they employed a paced word presentation, as had Perfetti et al. (1971). Upon comparison of their results with those of Wollen et al. (1980), however, Nelson et al. (1980) concluded that greater control over the experimental situation, as operationalized in part by paced presentation of the stimulus words, does not substantially alter the proportions of responses allocated to the various possible meaning categories. It is unclear, then, whether pacing is necessary in word-norm studies. However, all six of the meaning-norms studies described here required only a single response to each stimulus word. Paced presentation seems to be imperative if multiple responses to each stimulus word are collected, as was the case in the present study, in order to prevent subjects from listing many responses to the initial words and few responses to the final words in the stimulus word list.

The present study attempted to correct the various weaknesses of the existing meaning norms by (1) instructing subjects to respond to the stimulus words with meanings rather than with free associates, (2) collecting multiple rather than single responses to the stimulus words, (3) listing all meaning categories for each stimulus word, (4) listing the responses typical of the meaning categories as well as the meaning categories themselves, (5) randomizing the presentation order of the stimulus words for each subject, and (6) pacing the presentation of the stimulus words.

\section{METHOD}

\section{Subjects}

One hundred and ninety-seven students enrolled in an introductory psychology class at the University of Colorado served as subjects in partial fulfillment of course requirements. All subjects spoke English as their native language.

\section{Materials}

For many experimental purposes, the usefulness of a set of meaning norms is increased if the words in those norms have varying numbers of meanings. There is some evidence (Cartwright, 1977; Toglia et al., 1978, p. 12) that the number of meanings assigned to a given word is related to the rated concreteness of that word. Therefore, words having varying levels of rated concreteness were chosen for inclusion in the present meaning norms. Thirty of the 90 words had been used in the preliminary testing of hypotheses regarding the relationship between number of meanings and rated concreteness (Cartwright, 1977). These words had originally been drawn from the Paivio et al. (1968) normative list and were chosen so that 10 of the words would have high concreteness ratings (defined as a $C$ rating of 7.0 ), 10 would have medium concreteness ratings $(3.8 \leq \mathrm{C} \leq 4.2)$, and 10 would have low concreteness ratings $(1.0 \leq \mathrm{C} \leq 1.7)$. In order to ensure that the subjects would know each stimulus word, only words having fairly high meaningfulness ratings $(M>5.3)$ were selected.

In order to increase further the usefulness of these meaning norms to researchers of verbal learning and memory, the remaining 60 words were chosen from the Toglia et al. (1978), rather than from the Paivio et al. (1968), normative list. The Paivio et al. (1968) list contains normative information about the concreteness, imagery, and meaningfulness of each word in its collection, whereas the Toglia et al. (1978) list provides, for each word, normative information about familiarity, pleasantness, number of features, and categorizability, in addition to information about concreteness, imagery, and meaningfulness.

Although the concreteness ratings of words that appear in both the
Paivio et al. (1968) and the Toglia et al. (1978) normative lists are highly correlated across lists (Toglia et al., 1978, pp. 15-16), it was not possible to select from the Toglia et al. (1978) list enough highly meaningful homographic words for each concreteness level by using the same definitions of high, medium, and low concreteness that were used with the Paivio et al. (1968) words. In particular, there were not enough suitable words with concreteness ratings near 7.0, perhaps because the Toglia et al. (1978) list is not composed solely of nouns, as the Paivio et al. (1968) list is. Therefore, the following method was used to select words from the Toglia et al. (1978) list.

The frequency distribution of the concreteness ratings of the 2,854 words in the list was bimodal, with the modal points occurring at concreteness ratings of 3.0-3.5 and 5.5-6.0. This distribution was used to establish high, medium, and low concreteness levels. Words of high concreteness were defined as those having $\mathrm{C}$ ratings greater than or equal to the midpoint of the modal interval closest to the high-concreteness end of the distribution ( $\mathrm{C} \geq 5.75$ ). Words of low concreteness were defined as those having $C$ ratings less than or equal to the midpoint of the modal interval closest to the low-concreteness end of the distribution ( $C \leq 3.25$ ). Words of medium concreteness were then defined as those whose $\mathrm{C}$ ratings placed them in the lowest portion of the trough between the two modal points $(4.0 \leq \mathrm{C} \leq 5.0) .{ }^{1}$ These definitions essentially widened the possible range of the concreteness ratings of the words at each concreteness level. Words were selected such that there were 20 at each of the three concreteness levels. Because it was not possible to select enough suitable words with high meaningfulness ratings from the Toglia et al. (1978) list, only words with medium meaningfulness ( $3.5 \leq \mathrm{M} \leq 4.5$ ) were chosen. It is important to note that the meaningfulness ratings of words appearing in both the Paivio et al. (1968) and the Toglia et al. (1978) lists are not highly correlated; furthermore, the mean meaningfulness rating of the words in the Toglia et al. (1978) list is much lower than the mean meaningfulness rating of the same words in the Paivio et al. (1968) list. Toglia et al. (1978, pp. 15-16) suggested that the differences in rated meaningfulness result from the different methods by which meaningfulness was assessed in the two studies, and noted that comparisons of the meaningfulness of words across lists are at best questionable. The entire collection of 90 words is shown in Table 1.

In order to make the task a reasonable one for respondents to be able to complete within $1 \mathrm{~h}$, the list of 90 stimulus words was broken into two sets of 45 words each. Each set consisted of 5 words randomly selected from each of the Paivio et al. (1968) concreteness levels and 10 words randomly selected from each of the Toglia et al. (1978) concreteness levels. Each stimulus word was typed in capital letters at the top of a single page. A test booklet consisted of the $\mathbf{4 5}$ stimulus-word pages for a given word set plus a cover sheet of instructions. The order of the pages in each booklet was randomized so that the stimulus words were presented in a different order to each subject. Each subject received only one word-set booklet.

\section{Procedure}

The subjects were run in small groups of 10 to 20 . Test booklets were randomized before distribution so that within each small group some subjects received the first word set and some the second word set. The cover sheet instructions read as follows:

The purpose of this experiment is to find out what meanings people commonly give to various words. The procedure will be as follows: at the top of each page in this booklet is typed a word. You will be given 30 seconds to write down on the page beneath the word as many different meanings of the word as occur to you. in whatever order they occur to you. For example, if the word is MARK, you might write down the meanings

$$
\begin{aligned}
& \text { a boy's name } \\
& \text { to grade papers } \\
& \text { a foreign coin }
\end{aligned}
$$

etc. Please write only one meaning per line as shown in the example. When the 30 seconds are up, the experimenter will request that 
Table 1

Numbers of Meaning-Classes for Stimulus Words

\begin{tabular}{|c|c|c|c|c|c|c|c|c|c|c|c|}
\hline \multicolumn{12}{|c|}{ Concreteness Level } \\
\hline \multicolumn{4}{|c|}{ Low } & \multicolumn{4}{|c|}{ Medium } & \multicolumn{4}{|c|}{ High } \\
\hline Word & Source & MC & MCFR & Word & Source & $\mathrm{MC}$ & MCFR & Word & Source & MC & MCFR \\
\hline ANGER & $\mathbf{P}$ & 6 & 5 & ARCH & $\mathrm{T}$ & 25 & 20 & ARROW & $\mathbf{P}$ & 12 & 7 \\
\hline ANXIETY & $\mathbf{P}$ & 6 & 6 & BASE & $\mathbf{T}$ & 23 & 17 & AUTOMOBILE & $\mathbf{P}$ & 2 & 2 \\
\hline BEING & $\mathbf{T}$ & 6 & 6 & CAPITAL & $\mathrm{T}$ & 12 & 9 & BASIN & $\mathrm{T}$ & 9 & 7 \\
\hline CHANCE & $\mathbf{P}$ & 14 & 11 & $\mathrm{COACH}$ & $\mathrm{T}$ & 9 & 8 & BEAR & $\mathrm{T}$ & 19 & 5 \\
\hline CUSTOM & $\mathrm{T}$ & 6 & 5 & CRANK & $\mathbf{T}$ & 13 & 9 & BELT & $\mathrm{T}$ & 16 & 12 \\
\hline DEVOTION & $\mathbf{P}$ & 5 & 4 & DEED & $\mathbf{P}$ & 7 & 5 & BOW & $\mathrm{T}$ & 13 & 13 \\
\hline DROP & $\mathbf{T}$ & 33 & 9 & DISASTER & $\mathrm{P}$ & 4 & 3 & CAMEL & $\mathrm{T}$ & 9 & 3 \\
\hline EVEN & $\mathbf{T}$ & 22 & 15 & DYNASTY & $\mathrm{P}$ & 5 & 5 & CAR & $P$ & 5 & 2 \\
\hline FAULT & $\mathrm{T}$ & 8 & 6 & FELT & $\mathbf{T}$ & 6 & 4 & CARDINAL & $\mathrm{T}$ & 11 & 9 \\
\hline FLOW & $\mathbf{T}$ & 26 & 21 & FILE & $T$ & 14 & 12 & COLLAR & $\mathrm{T}$ & 16 & 11 \\
\hline GRACE & $\mathrm{T}$ & 12 & 7 & FLUSH & $\mathbf{T}$ & 17 & 13 & COTTON & $\mathrm{T}$ & 13 & 9 \\
\hline IDEAL & $\mathbf{T}$ & 6 & 5 & FUZZY & $\mathrm{T}$ & 6 & 5 & DOUGH & $\mathrm{T}$ & 7 & 4 \\
\hline IN & $\mathrm{T}$ & 16 & 9 & HAIL & $\mathrm{T}$ & 10 & 7 & EMERALD & $\mathrm{T}$ & 8 & 5 \\
\hline INTEREST & $\mathrm{T}$ & 10 & 7 & LEAD & $\mathrm{T}$ & 14 & 10 & HEEL & $\mathrm{T}$ & 8 & 5 \\
\hline JOY & $\mathbf{P}$ & 4 & 3 & LEGISLATION & $\mathbf{P}$ & 3 & 3 & KEY & $\mathrm{T}$ & 19 & 8 \\
\hline KNOWLEDGE & $\mathbf{P}$ & 4 & 4 & LORD & $\mathbf{P}$ & 12 & 10 & MICROSCOPE & $\mathrm{P}$ & 1 & 1 \\
\hline LOYALTY & $\mathrm{P}$ & 2 & 2 & MARRIAGE & $\mathbf{P}$ & 8 & 5 & MOLE & $\mathrm{T}$ & 14 & 4 \\
\hline MEMORY & $\mathrm{T}$ & 7 & 3 & MASS & $\mathrm{T}$ & 11 & 7 & OLIVE & $\mathrm{T}$ & 12 & 6 \\
\hline MIGHT & $\mathrm{T}$ & 2 & 2 & MINE & $\mathrm{T}$ & 5 & 4 & PAGE & $\mathrm{T}$ & 11 & 6 \\
\hline MOOD & $\mathbf{P}$ & 7 & 6 & PILE & $\mathrm{T}$ & 11 & 8 & PALM & $\mathbf{T}$ & 14 & 3 \\
\hline MORAL & $\mathbf{P}$ & 7 & 6 & PLOT & $\mathrm{T}$ & 11 & 8 & PENCIL & $\mathrm{P}$ & 3 & 2 \\
\hline PARDON & $\mathrm{T}$ & 7 & 5 & PRESENT & $\mathbf{P}$ & 9 & 7 & SHELL & $\mathrm{T}$ & 23 & 8 \\
\hline PASS & $\mathrm{T}$ & 23 & 14 & ROLL & $\mathrm{T}$ & 27 & 12 & SKIRT & $\mathrm{T}$ & 10 & 4 \\
\hline PASSION & $\mathbf{P}$ & 15 & 9 & SERIES & $\mathbf{P}$ & 7 & 6 & STRAWBERRY & $\mathbf{P}$ & 13 & 6 \\
\hline RAISE & $\mathrm{T}$ & 11 & 7 & SHOCK & $\mathbf{P}$ & 32 & 24 & TAIL & $\mathrm{T}$ & 14 & 9 \\
\hline REFINED & $\mathrm{T}$ & 6 & 6 & SLIP & $\mathrm{T}$ & 24 & 9 & THREAD & $\mathrm{T}$ & 12 & 6 \\
\hline RULE & $\mathrm{T}$ & 14 & 10 & SWALLOW & $\mathrm{T}$ & 8 & 6 & TREE & $\mathrm{P}$ & 7 & 4 \\
\hline SOUL & $\mathrm{T}$ & 10 & 9 & VISION & $\mathrm{P}$ & 10 & 8 & TRUCK & $\mathbf{P}$ & 14 & 8 \\
\hline THINNER & $\mathrm{T}$ & 5 & 5 & WELL & $\mathrm{T}$ & 10 & 8 & TRUMPET & $\mathrm{P}$ & 16 & 3 \\
\hline UTTER & $\mathrm{T}$ & 2 & 2 & WRAP & $\mathrm{T}$ & 18 & 12 & WINDOW & $\mathbf{P}$ & 6 & 5 \\
\hline
\end{tabular}

Note-P = words drawn from Paivio et al. $(1968) . T=$ words drawn from Toglia et al. $(1978)$. MC $=$ number of meaning-classes for all responses. $M C F R=$ number of meaning-classes for first responses.

you turn the page. You are to stop writing immediately and turn to the next page where there will be another word for which you are to write down meanings. This procedure will be repeated for a total of 45 words.

Should it happen that you are unable to read a word because it is too lightly printed, wait quietly until the 30 seconds for that word are up and then when the experimenter requests you to turn the page, turn the page and begin writing meanings for the next word

Do not turn the page until told to do so.

The 30 -sec intervals were timed with a standard stopwatch.

\section{RESULTS AND DISCUSSION}

Meanings for the stimulus words in the first and second word sets were listed by 96 and 101 subjects, respectively. A single meaning listed for a stimulus word will hereafter be termed a "meaning-response." The actual phrasing of a meaning-response is called a "meaning-expression." The difference between the terms meaning-response and meaning-expression is rather subtle and is best illustrated by an example. If 12 subjects have listed "a scoundrel" for the stimulus word HEEL, there are 12 meaning- responses but only 1 meaning-expression. Within a single subject, however, a meaning-response is the meaningexpression of that response; listing "a scoundrel" in response to HEEL is both that subject's meaning-response and his or her meaning-expression of that response. The legible meaning-expressions listed by subjects for any particular stimulus were categorized as (1) MEANINGS, (2) CONFUSIONS, (3) MISTAKES, (4) ASSOCIATES, or (5) BLANKS.

\section{MEANINGS}

If a meaning-expression listed by a subject as his or her meaning-response to a given stimulus word could be found in a dictionary, thesaurus, slang dictionary, technical reference, foreign language dictionary, or other published reference work, or was recognized as being a common usage of the stimulus word, it was accepted as a legitimate MEANING of the word. Legitimate MEANINGS included:

1. dictionary-style definitions

examples: LEAD_" "the starring role" MOLE_"a dark spot on the skin" 
2. synonyms

examples: BASIN_"a washbowl",

ANGER-"wrath"

3. names of persons or the meaning expression "a name"

examples: JOY_"“a girl's name",

ARCH-"short for Archie"

4. geographical place names

examples: EMERALD_“a bay in North Lake

Tahoe"

PALM-"Palm Springs"

5. names of sport teams

examples: CARDINAL_" "a football team"

BEAR - "a team name"

6. slang terms

examples: CRANK-"heroin"

BEAR - "something that is hard to do"

7. definition by example

examples: AUTOMOBILE_-"Chevy"

DYNASTY - "Ming Dynasty"

8. metaphorical, poetic, or symbolic usage examples: BEAR - "someone who is big"

MOLE - "a person with small eyes"

OLIVE-“a peace symbol"'

9. the completion of a phrase in which the word is often found

examples: CAPITAL_-"capital punishment" CARDINAL_ "a cardinal sin"

10. commercial product names, including beverage names, brand names, and company names

examples: JOY_-"a dishwashing liquid"

ARROW - "a shirt company"

PASSION-"a drink"

11. technical or specialized terms

examples: CAMEL_“'a skiing or iceskating maneuver"

FILE-"a deck of cards [computer science term]"

12. abbreviations

examples: MASS_" "the abbreviation of Massachusetts"

CUSTOM-"short for customers"
13. foreign words

examples: DROP_-"licorice in Dutch"

PARDON-"a French word",

14. parts of words

$$
\begin{aligned}
& \text { examples: IN_-"a prefix" } \\
& \text { IN_-"a reagent in chemistry [suf- } \\
& \text { fix]" }
\end{aligned}
$$

15. interjections, exclamations, and expressions

$$
\begin{aligned}
& \text { examples: WELL_-"expression", } \\
& \text { PARDON_-"sorry"' } \\
& \text { HAIL_-"Southern pronunciation of } \\
& \text { "hell'", }
\end{aligned}
$$

16. references to games, groups, records, and songs

$$
\begin{gathered}
\text { examples: ARROW_-"a card game" } \\
\text { CHANCE_-"a Monopoly card" } \\
\text { DEVOTION_"a song by Earth } \\
\text { Wind and Fire" }
\end{gathered}
$$

17. names of flowers, trees, and plants

$$
\begin{aligned}
& \text { examples: PASSION_-"a flower", } \\
& \text { COTTON_-"a plant" }
\end{aligned}
$$

18. book titles and characters and places in books, in the movies, or on television

$$
\begin{gathered}
\text { examples: OLIVE-_"Popeye's girl friend" } \\
\text { EMERALD_-"Emerald City (in The } \\
\text { Wizard of Oz)" }
\end{gathered}
$$

Different meaning-expressions denoting the same underlying idea were combined into a single "meaningclass." Thus, the meaning-expressions "a fool," "a bad guy," "a jerk," " a fink," " an undesirable character," "a cad," " a scoundrel," and "a creep" for the stimulus word HEEL were all combined into the same meaningclass. In most cases, this combination could be performed on the basis of common sense, although occasionally it was necessary to consult one or more dictionaries. A check for combination reliability was performed for a small, randomly chosen subset of the stimulus words. An independent coder was given a list of the possible meaning-classes for each word in the subset and was asked to assign each MEANINGS meaning-response for that word to the appropriate meaning-class. Agreement with the original assignment of meaning-responses to meaningclasses was very high, ranging from $91 \%$ (for VISION) to $100 \%$ (for EMERALD).

The term "meaning-class" is equivalent to the terms "meaning category" and "sense category" used in other meaning-norms studies. Any one meaning-class may be composed of meaning-expressions representing one or several of the different kinds of legitimate MEANINGS 
listed above. Indeed, because legitimate kinds of MEANINGS are not mutually exclusive, one meaning-expression may itself represent more than one kind of legitimate MEANING. Generally, however, a meaning-class contains meaning-expressions that belong to only one syntactical class; that is, the meaning-expressions within a meaningclass will refer only to nouns or only to verbs, etc. The set of all meaning-classes for a stimulus word constitutes the MEANINGS category of the stimulus word. The number of meaning-classes in the MEANINGS category of each stimulus word is shown in Table 1 . The number of meaning-classes was tabulated both for first responses and for all responses to each stimulus word.

Table 2 lists MEANINGS meaning-classes for each stimulus word. The different meaning-expressions within a meaning-class are separated by commas and are shown exactly as the subjects wrote them, except that punctuation and spelling have been changed to conform to normal English usage, the article "a," "an," or "the" has been added to meaning-expressions that are nouns or noun phrases, and the infinitive form is always given for meaning-expressions that are verbs or verb phrases. The meaning-expressions listed for a meaning-class are not exhaustive; there may be other meaning-expressions that belong to a meaning-class that are not listed. An effort was made to select the most frequent or most representative examples of the meaning-expressions included in a meaning-class as exemplars of that meaning-class, in order to prevent the repetition of meaning-expressions that are trivially different.

For each stimulus word, Table 2 lists the frequency of responses (F) and the frequency of first responses $[\mathrm{F}(\mathrm{lst})]$ in each MEANINGS meaning-class. Because it was possible for a subject to list as meaning-responses more than one meaning-expression belonging to a meaning-class, the sum of the response frequencies totaled across all meaning-classes may be greater than the number of subjects. The sum of the first-response frequencies totaled across meaning-classes must, of course, be less than or equal to the number of subjects. Meaningresponses were not tabulated separately for male and female subjects, because Kausler and Kollasch (1970) and Wollen et al. (1980) have shown that the proportions of meanings assigned to each meaning category by males and by females are very nearly perfectly correlated.

\section{CONFUSIONS}

The second category of meaning-expressions shown in the tables is CONFUSIONS. A CONFUSION occurred when a subject mistook the spelling of a stimulus word to be that of another word having a similar or identical pronunciation. Thus, the meaning-expression "a milk bag" for UTTER is a CONFUSION for the word UDDER. In order for a subject's meaning-expression to be classified as a CONFUSION, he or she must have listed as meaning-responses to the stimulus word other meaningexpressions that could be classified as legitimate MEANINGS of that word, as described above. CONFUSIONS meaning-expressions were grouped into meaning-classes and tabulated in the same way as MEANINGS meaningexpressions. The interpretations of $F$ and $F(1 s t)$ for $\mathrm{CON}$ FUSIONS meaning-classes are analagous to those for MEANINGS meaning-classes.

\section{MISTAKES}

A MISTAKE occurred when a subject misread a stimulus word as a completely different word and listed meaning-responses for that word rather than for the stimulus word. For example, four subjects misread MIGHT as RIGHT and listed meaning-responses for RIGHT, and one subject misread MIGHT as MIDGET and listed meaning-responses for MIDGET. Subjects whose meaning-responses to a stimulus word were classified as MISTAKES never listed as meaningresponses meaning-expressions that could be classified as legitimate MEANINGS of that word. MISTAKES could occur either because a stimulus word was poorly printed and therefore unreadable or because the subject, working under a time limit, did not read the stimulus word carefully before beginning to list meaning-responses. The first possibility does not seem to have occurred very often.

The meaning-expressions for MISTAKES were not grouped into meaning-classes, as the meaning-expressions for MEANINGS and CONFUSIONS were. Instead, an entry in Table 2 merely states that the stimulus word was mistaken to be some other word, specifies that other word, and gives the number of subjects $(F)$ who misread the stimulus word to be that other word. $F(1 \mathrm{st})$ has the same interpretation as $\mathrm{F}$ for MISTAKES.

\section{ASSOCIATES}

When a meaning-expression could not be classified as a MEANING, a CONFUSION, or a MISTAKE, it was considered an ASSOCIATE. Thus, "contact lens" was an ASSOCIATE of VISION, and "chipped" was an ASSOCIATE of BASIN. Subjects who listed ASSOCIATES as meaning-responses to the stimulus words usually listed legitimate MEANINGS as well. The ASSOCIATES generally referenced MEANINGS already listed. For example, a subject who responded to BASIN with the ASSOCIATE "chipped" was also likely to have listed the MEANING "washbowl." It appears that subjects most often listed ASSOCIATES for stimulus words for which they could think of few meanings, in order to fill up the 30-sec interval for listing responses. Because of this duplication and because the instructions specifically requested that subjects list meanings, ASSOCIATES were not considered legitimate meaning-responses to the stimulus words and are not reported in Table 2.

\section{BLANKS}

The fifth category, BLANKS, occurred (1) when a subject listed no meaning-responses to a stimulus word, (2) when a subject listed no meaning-responses that could be classified as MEANINGS, CONFUSIONS, or MISTAKES meaning-expressons (i.e., he or she listed 
only ASSOCIATES), or (3) when a word page was somehow missing from a subject's word set. F indicates the number of subjects for whom a given stimulus-word page was BLANK. $\mathrm{F}(1 \mathrm{st})$ has the same interpretation as $\mathrm{F}$ for BLANKS.

\section{Word Tables}

Each word table within Table 2 lists the MEANINGS, CONFUSIONS, MISTAKES, and BLANKS for each stimulus word. The word tables are arranged in alphabetical order. Each word table indicates the number of subjects $(n=96$ or $n=101)$ listing meaning-responses for that stimulus word. As noted above, the meaningexpressions in the meaning-classes for MEANINGS and CONFUSIONS are given exactly as written by the subjects. Any comments or clarifications by the authors are enclosed in square brackets. Some of the more common clarifications occur:

1. when it is unclear whether the meaning-expressions in a MEANINGS or CONFUSIONS meaning-class refer to the noun form or to the verb form of a stimulus word that can be interpreted as either a noun or a verb

$$
\begin{gathered}
\text { example: ARCH - "to curve" } \\
\text { - "a curve" } \\
\text {-"“curve [noun or verb unspeci- } \\
\text { fied]" }
\end{gathered}
$$

2. when the meaning-expressions in a MEANINGS or CONFUSIONS meaning-class for a stimulus word that is an emotion do not specify the exact nature of the emotion but merely state "an emotion" or "a feeling"

example: ANGER -“"madness, being mad, hatred, ire, wrath, fury, hostility"

-" "an emotion, a feeling [unspecified]"

3. when it may not be immediately apparent that the meaning-expressions in a MEANINGS or CONFUSIONS meaning-class refer to the slang usage of the stimulus word

example: CRANK_-"speed, heroin [slang]"

4. when the underlying denotation of a MEANINGS or CONFUSIONS meaning-class may not be immediately obvious

example: ANXIETY - "nervousness, uneasiness, fear, apprehension, tenseness, uptightness, worried anticipation [a negative emotion]"

-"anticipation, expectancy, anxiousness [a neutral emotion]"

- "eagerness, longing, hopefulness [a positive emotion]"

5. when a MEANINGS or CONFUSIONS meaningclass consists of many meaning-expressions that are definitions by example

example: CAR - "an automobile, a vehicle, an auto, a motor vehicle [and any specified make of car]",

\section{6. as explanations of CONFUSIONS}

example: THREAD-"a tire surface [confusion with tread]"

7. as explanations of MISTAKES

example: SOUL_-"[word mistaken as SOUR]"

The MEANINGS meaning-classes, CONFUSIONS meaning-classes, and MISTAKES explanations in each table are ordered from most to least frequent occurrence within their respective categories, that is, from highest to lowest $F$. If the Fs for two (or more) meaning-classes are equal, the meaning-classes are listed in order from highest to lowest $F(1 \mathrm{st})$. In all but one of the previously published meaning norms (Nelson et al., 1980), the frequency of response for each meaning-class is reported as a percentage of the total number of responses across all meaning-classes. In the present meaning norms, however, frequencies rather than percentages are reported, in order to allow researchers more flexibility in using the norms. For example, some researchers may wish to consider CONFUSIONS to be legitimate meaning-responses to a particular stimulus word, particularly if there are many of them (as is the case with UTTER, for example). Considering CONFUSIONS to be legitimate meaningresponses changes the percentage of responses in each meaning-class from what it would be if only MEANINGS were considered legitimate meaning-responses. In addition, some researchers may wish to eliminate or combine meaning-classes. Implementing these options is simplified if frequencies rather than percentages are reported. It should be noted, however, that percentages should be computed before comparisons are made across words, because half the words have an $\mathrm{n}$ of 96 and half the words have an $\mathrm{n}$ of 101 .

When the number of BLANKS for a stimulus word exceeds 5 , an explanation is given in a footnote to the table 
for that word. The number of BLANKS exceeds 5 for 13 stimulus words. The high number of BLANKS for the word OLIVE is due to this word page having been inadvertently omitted from several word booklets. The high numbers of BLANKS for the remaining 12 words are primarily due to the large numbers of subjects who listed only ASSOCIATES (and no MEANINGS) as meaningresponses to the stimulus words. Of these 12 words, 7 were of low concreteness, 3 of medium concreteness, and 2 of high concreteness. Although the distribution of these words across concreteness levels is not significantly different from that which would be expected by chance, it does suggest that subjects find it difficult to define abstract words.

\section{Concreteness and Number of Meaning-Classes}

It was mentioned earlier that there is some evidence that the number of meanings assigned to a given stimulus word is related to the rated concreteness of that word. Cartwright (1977) suggested that the semantic attribute of abstractness-concreteness is a categorical attribute rather than a continuous dimension, as is generally assumed. That is, any given stimulus word either is concrete $(C=7.0)$, referring to "objects, materials, or persons" (Paivio et al., 1968, p. 5), or is abstract $(C=1.0)$, referring to "concepts that cannot be experienced with the senses" (Paivio et al., 1968, p. 5). Why, then, do stimulus words have concreteness ratings that indicate an intermediate level of concreteness (i.e., $1.0<\mathrm{C}<7.0$ )? Cartwright reasoned that words seem to vary in concreteness because they may have many meanings, some of which are abstract and some of which are concrete. When subjects rate the concreteness of a stimulus word (e.g., DEED), some will think of the concrete meanings of that word and rate those (DEED = "a legal document"), and others will think of the abstract meanings and rate those (DEED = "an action"). When the concreteness ratings of the word are averaged across subjects, the mean rating will be a value near 4.0 , seemingly reflecting a medium level of concreteness. Deviations from a mean of 4.0 then reflect the proportions of subjects rating abstract and concrete meanings.

One implication of this reasoning is that stimulus words of medium concreteness should have more first-response meaning-classes than do words of low or high concreteness. (Cartwright, 1977, assumes that any particular subject will think of only one meaning of a stimulus word-that is, the first meaning-when rating the concreteness of that word. Therefore this analysis is performed only for first-response meaning-classes.) A oneway analysis of variance performed on the number of firstresponse meaning-classes for words of low, medium, and high concreteness shows a small but significant effect of concreteness level on number of meaning-classes $[F(2,87)=3.88, p<.05$, eta $=.29]$. A Newman-Keuls test shows that, as hypothesized, the number of firstresponse meaning-classes for words of medium con-

creteness (mean $=8.80$ ) is significantly greater than the number of first-response meaning-classes for words of high concreteness (mean $=5.90$ ). However, the number of first-response meaning-classes for words of medium concreteness is not significantly greater than the number of first-response meaning-classes for words of low concreteness (mean $=6.97$ ). This lack of significance is evidently due to the existence of outliers. Accordingly, the minimum and the maximum numbers of first-response meaning-classes were "trimmed" (Winer, 1971, pp. 51-54) from each concreteness level. A one-way analysis of variance performed on the trimmed data also shows a small but significant effect of concreteness level on number of first-response meaning-classes $[F(2,81)=4.72, p<.05$, eta $=.32]$. A Newman-Keuls test then shows that the number of first-response meaningclasses for words of medium concreteness (mean $=8.46$ ) is significantly greater than the number of first-response meaning-classes for words of high concreteness (mean $=5.82$ ) and for words of low concreteness $($ mean $=6.64)$.

The fact that words of medium concreteness have significantly more first-response meaning-classes than do words of either low or high concreteness does not, of course, lead to the conclusion that concreteness is a categorical, rather than a continuous, semantic attribute as has been assumed. It does, however, lend support to that proposition, as do findings of Toglia et al. (1978, p. 12). More research investigating this interesting and unusual view of semantic concreteness is needed.

Table 2

University of Colorado Meaning Norms

F $\quad F(1 s t)$

ANGER $(n=101)$

MEANINGS

madness, being mad, hatred, ire, wrath,

fury, hostility

an emotion, a feeling [unspecified]

frustration

to get someone else angry, to make

someone mad, to irritate, to enrage

to become angry

a name

76

25

22

13

CONFUSIONS

airplane anger [confusion with airplane hangar]

clothes anger [confusion with clothes

hanger]

MISTAKES

BLANKS

ANXIETY $(n=101)$

\section{MEANINGS}

nervousness, uneasiness, fear, apprehension, tenseness, uptightness, worried anticipation [a negative emotion]

(1st)

(1st) 
Table 2 (continued)

\begin{tabular}{|c|c|c|}
\hline & $\mathrm{F}$ & $\mathrm{F}(1 \mathrm{~s}$ \\
\hline $\begin{array}{l}\text { anticipation, expectancy, anxiousness } \\
\text { [a neutral emotion] }\end{array}$ & 15 & 6 \\
\hline $\begin{array}{l}\text { an emotional state, an emotion, feelings } \\
\text { [unspecified] }\end{array}$ & 14 & 12 \\
\hline stress & 7 & 6 \\
\hline $\begin{array}{l}\text { eagerness, longing, hopefulness [a } \\
\text { positive emotion] }\end{array}$ & 7 & 2 \\
\hline a psychological term, a Freudian term & 3 & 2 \\
\hline CONFUSIONS & 0 & 0 \\
\hline MISTAKES & 0 & 0 \\
\hline BLANKS* & 7 & 7 \\
\hline
\end{tabular}

*The high number of BLANKS is due to the large number of subjects who listed only associates and no meanings.

$$
\text { ARCH }(n=101)
$$

\section{MEANINGS}

a part of the foot, the curve in one's foot

a building structure, an architectural

term, a structure

a hallway, a gate, an archway, a

tunnel [the notion of entryway]

a bent line, a rainbow shape, a shape

like this $\cap, \cap$, half of a circle, a half

circle shape

to bend, to curve, to lean back

a part of a bridge, a bridge

the St. Louis landmark, the Arc de

Triomphe, a monument

a part of the back

most, top, highest (as in arch enemy)

bend, curve [noun or verb unspecified]

short for Archie, a name

a curved structure

a movement, a movement of the body

a curve, something curved, anything

curved

a structural support, a support

to arch, to engage in archery

a natural formation, a rock formation

to describe an arched course

a part of a shoe

to raise an eyebrow

a rainbow

a parachuting position

a part of the mouth

mean

a trajectory

CONFUSIONS

a boat [confusion with ark]

MISTAKES

BLANKS

ARROW $(n=96)$

\section{MEANINGS}

weaponry, a bow and arrow, a projectile, a hunting weapon, a spear
Table 2 (continued)

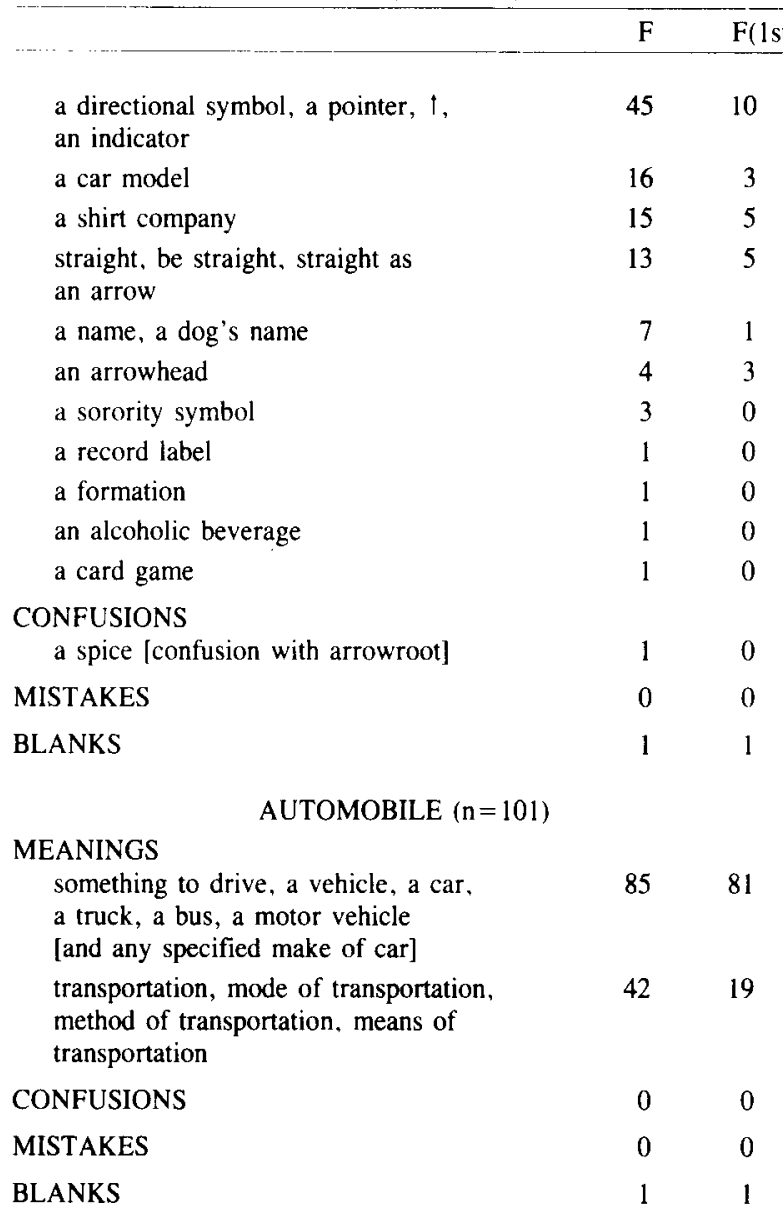

$\operatorname{BASE}(n=101)$

\section{MEANINGS}

first base, a part of a baseball diamond, home plate [and any reference to baseball] the bottom of an object

a foundation, what something is built upon, a support

an army base, a military installation, military headquarters [military specified]

alkaline, not acid, opposite of acid, a solution

coarse, vulgar, crude, lowly, common, primitive

a pedestal, a stand, a platform

the beginning, where you begin, the starting point

a home office

a home base [unclear whether reference

is to baseball or to a home office]

the main part, the main purpose, a basis $\quad 7 \quad 5$

a station, an installation [military not $\quad 4 \quad 1$

specified]

a square root, a mathematical root

the main mixture

a mathematical term

a safe place

a triangle part, a geometric term

$\begin{array}{ll}60 & 24 \\ 32 & 22 \\ 23 & 11 \\ 22 & 4 \\ 21 & 8 \\ 17 & 4 \\ 14 & 6 \\ 14 & 1 \\ & \\ 10 & 5 \\ 10 & 2 \\ & \\ 7 & 5 \\ 4 & 1 \\ & \\ 3 & 1 \\ 3 & 1 \\ 3 & 0 \\ 3 & 0 \\ 2 & 1\end{array}$


Table 2 (continued)

\begin{tabular}{|c|c|c|}
\hline & $\mathbf{F}$ & $\mathrm{F}(1 \mathrm{st}$ \\
\hline the amount of snow & 2 & 1 \\
\hline the bottom of a column & 1 & 1 \\
\hline a goal & 1 & 0 \\
\hline a baseboard & 1 & 0 \\
\hline a name & 1 & 0 \\
\hline a root word & 1 & 0 \\
\hline \multicolumn{3}{|l|}{ CONFUSIONS } \\
\hline $\begin{array}{l}\text { a drum, a cello, a musical instrument, } \\
\text { a guitar [confusion with bass] }\end{array}$ & 10 & 3 \\
\hline $\begin{array}{l}\text { the lower key in music [confusion with } \\
\text { bass] }\end{array}$ & 8 & 0 \\
\hline remedial [confusion with basic] & 1 & 0 \\
\hline MISTAKES & 0 & 0 \\
\hline BLANKS & 0 & 0 \\
\hline
\end{tabular}

\section{MEANINGS}

BASIN $(n=96)$

a washbowl, a washbasin, a tub, a sink,

a waterbowl [a water container]

a geographical feature, a bowl-like valley, a dried lake, a lowland

a bowl, a container

a pool, an enclosed water area, a lake,

a launch [an aquatic geographical feature]

a hollowed area, a depression [not

specifically geographical]

a ski resort

Basin Street New Orleans, Basin

Street Blues

basin tub and tile cleaner, tub and tile

a bird bath

\section{CONFUSIONS}

a musical instrument [confusion with bassoon]

\section{MISTAKES}

BLANKS

BEAR $(n=101)$

\section{MEANINGS}

an animal, a furry animal, a polar bear, ursa [and any specified type of bear]

to put up with, to tolerate, to stand,

to withstand, to endure

to support, to carry, to hold

a grouch, a grump, a mean person

something that is hard to do, a difficult

task

a name, a nickname

to put pressure on, to bear down

a kind of hug

to have, to possess

a team name

to act oppressively, to be overbearing

to have children

a drink

a toy

a rug
Table 2 (continued)

F

$\mathrm{F}(1 \mathrm{st})$

to produce

to give

to give as testimony, to tell a lie

someone who is big

10

10

CONFUSIONS

naked, nude [confusion with bare]

to lay bare, to uncover [confusion with bare]

MISTAKES

BLANKS

\section{MEANINGS \\ existing, existence, living, surviving}

a person, a human being [human]

the verb form of be, is, a present tense

a creature, something that lives or

exists [human not specified]

the self, the soul, the spirit

God

\section{CONFUSIONS}

MISTAKES

BLANKS

BELT $(\mathrm{n}=101)$

\section{MEANINGS}

something to hold up pants, an article of clothing, goes around the waist, tightens dresses and skirts, suspenders

to hit, to slug, to punch, to spank, to hit someone, to strike

a drink, a shot of whiskey, a drink of liquor, a stiff drink

a zone, an area, a geographical area, a region, the corn belt, the green belt hit, punch, slug [unspecified noun or verb]

a drive part, goes with a pulley, a fan belt

a hit, a punch, a hard blow

to drink, to drink whiskey

drink [unspecified noun or verb]

a conveyor belt, something used to send

\section{packages up a ramp}

a seat belt

a strap, a strip

anything which encircles

a karate level

a name

to fasten

CONFUSIONS

MISTAKES

BLANKS

$$
\text { BOW }(\mathrm{n}=96)
$$

\section{MEANINGS}


Table 2 (continued)

a ribbon, a hair ribbon, a package ribbon to bend down at the waist, to curtsey the front of a ship, a part of a boat a bow tie, a necktie curtsey [unspecified noun or verb] a curtsey, a formal gesture, a gesture of respect, a man's greeting bow-wow, a dog's bark to bend

a part of a musical instrument a bow knot

a bend, an arc

bend [unspecified noun or verb]

CONFUSIONS

a boyfriend [confusion with beau]

a branch [confusion with bough]

a boy's name [confusion with Beau]

MISTAKES

[word mistaken as ROW]

BLANKS

CAMEL $(n=101)$

MEANINGS

an animal, a humped animal, a desert animal, a dromedary

a cigarette brand

a tan color, a color, beige

a soft material, a material used for coats

a group's name

a World War I plane

a name

a paintbrush

a skiing or iceskating maneuver

CONFUSIONS

MISTAKES

BLANKS

CAPITAL $(n=101)$

\section{MEANINGS}

money, money accumulated, money

free to use, money for investments, income

a city, the main city, the main city of a state, the main city of a country [city specified]

capital letters, large letters, uppercase letters

the government, an important place for leaders, the political area of a state, the seat of government [government specified]

the head of a state, the primary area of a state [neither city nor government specified]

gains and losses, gathered goods

possessions, property

good, excellent

important, central, primary
Table 2 (continued)

F $\mathrm{F}$ (lst)

capital punishment, punishment

the center of importance

the capitalistic system

an architectural term

$\begin{array}{ll}4 & 1 \\ 3 & 3 \\ 2 & 0 \\ 1 & 0\end{array}$

CONFUSIONS

a building [confusion with capitol]

195

MIST AKES

$0 \quad 0$

BLANKS

$0 \quad 0$

CAR $(n=96)$

MEANINGS

an automobile, a vehicle, an auto, a motor vehicle [and any specified make of car]

transportation, means of transportation

a train unit

a toy

a part of a ride at the carnival

89

88

CONFUSIONS

MISTAKES

BLANKS

CARDINAL $(n=96)$

MEANINGS

a bird, a red bird

$84 \quad 50$

a religious official, a religious office,

$77 \quad 28$

a priest, a Catholic official, a Catholic

office, a Catholic priest, a religious ruler [reference to "Catholic" or to

"religious"]

a baseball team, a football team, a team name

a color, red

primary, chief, important, principal, first

a cardinal sin

the cardinal numbers, a mathematical term $\quad 13 \quad 2$

the cardinal rule

a flower

a name

the points of the horizon

CONFUSIONS

MISTAKES

BLANKS

CHANCE $(n=96)$

\section{MEANINGS}

an opportunity, a try

a gamble, a risk, a guess, a dare, a bet

$41 \quad 26$

fate, luck, fortune

$40 \quad 18$

$34 \quad 14$

$17 \quad 10$

circumstance, a random event, an uncertain event

probability, odds, percentage, likelihood $\quad 17 \quad 9$ possibility, maybe, could be

$12 \quad 4$

to try something, to take a risk, to "chance it" 
Table 2 (continued)

\begin{tabular}{lll}
\hline & F & F(lst) \\
\hline a name & 7 & 2 \\
a game & 6 & 1 \\
a Monopoly card & 5 & 4 \\
a lottery ticket, a raffle ticket & 3 & 1 \\
a cigarette brand & 1 & 0 \\
to come upon, to find & 1 & 0 \\
a music group & 1 & 0 \\
CONFUSIONS & & \\
$\quad$ [confusion with change] & 5 & 2 \\
MISTAKES & 0 & 0 \\
BLANKS & 2 & 2
\end{tabular}

Table 2 (continued)

\begin{tabular}{lll}
\hline & $F$ & $F(1$ \\
\hline a binding, something that goes around & 2 & 1 \\
an arrest & 2 & 1 \\
to hit & 2 & 1 \\
a chemistry instrument & 1 & 0 \\
CONFUSIONS & & \\
$\quad$ a disease [confusion with cholera] & 2 & 0 \\
greens [confusion with collards] & 1 & 0 \\
MISTAKES & 0 & 0 \\
BLANKS & 2 & 2
\end{tabular}

MEANINGS

an instructor in a sport, a sports teacher, a supervisor in sports or athletics, the leader of an athletic team, a teacher of athletics [reference to sports]

a carriage, a buggy, a stage, a horsedrawn vehicle, a conveyance, a wagon, a vehicle, an Old West vehicle to help, to instruct, to advise, to guide, to teach, to encourage [no reference to sports]

a tutor, a helper, a supervisor, a leader, a teacher, an advisor, a manager [no reference to sports]

a type of plane fare, an airplane fare, second class, certain seats on an airline to train an athletic team, to lead a team, to guide a team, to teach a team [reference to sports]

a nickname for an instructor

a name for a bus

a type of shoe

\section{CONFUSIONS}

a sofa [confusion with couch]

\section{MISTAKES}

BLANKS

$$
\text { COLLAR }(n=101)
$$

\section{MEANINGS}

a shirt collar, a coat collar, a part of

a shirt

a dog collar, an animal collar

to grab, to arrest, to catch, to capture

anything that circles the neck

the status of a worker, blue collar,

white collar

a necklace

a preacher's collar, a priest's collar

an edge, a rim

a restraint

to put a collar on

a machine collar, a tool collar

to encircle, to surround, to go around

2
0
]

\section{MEANINGS}

$$
\text { COTTON }(n=96)
$$

a fabric, a cloth, a material, a clothing

material for making shirts

$\begin{array}{lll}\text { a plant } & 43 & 21 \\ \text { a ball of cotton, a fluffy white ball, } & 26 & 15\end{array}$

a cosmetic puff

a cotton boll, a soft ball picked from a

plant, a seed ball

to like, to be in harmony with

a fiber

a name, a last name, an animal's name

candy

$$
\text { a swab }
$$

a feeling in your mouth, a dryness of the mouth

a tree

cottonmouth [unclear whether reference is to mouth dryness or to a snake]

$$
\text { a kind of oil }
$$

CONFUSIONS

\section{MISTAKES}

BLANKS

\section{CRANK $(n=101)$}

\section{MEANINGS}

to turn something, to wind, to turn 68 a handle

a crabby person, a mean person, a grump, $\quad 65$ someone in a bad mood

something to turn, a handle, a shaft, a tool, a lever

to start up (as a car or engine)

a part of a car machinery, a part of a machine

a crank call, a prank call

an eccentric, a fool, a crazy person

a prank, a joke

speed, heroin [slang]

fake, phony, false

a noise

to shift

a penis [slang]

CONFUSIONS

$\mathrm{F}(1 \mathrm{st})$

$$
1
$$
1 (1)

0


Table 2 (continued)

MISTAKES
BLANKS
MEANINGS
a tradition, the ways of society, a ritual,
norms, social ways of behaving, cultural
practices [reference to a cultural or
societal way of doing things]
individually made, custom made,
personally made, made to order, made to
individual specifications
a baggage check, a check when entering
another country
a habit, an individual's way of doing
something [reference to a personal way of
doing things]
customary, what's usual, something
always done, everyday things, a usual way
of doing something [cultural or personal way
of doing things not specified]
short for customers
CONFUSIONS
MISTAKES
BLANKS

\section{MEANINGS}

$$
\text { DEED }(n=96)
$$

a property title, a writ of ownership, proof of ownership, a lease, a mortgage, a land title, a will [document of property ownership implied]

an action, something that is done, an event, an act

a good action, a favor, a kind act

a legal document, a contract, an

agreement [document, ownership of property not implied]

a bad action

a last name

to give title to property

\section{CONFUSIONS}

\section{MISTAKES}

BLANKS

\section{DEVOTION $(n=101)$}

\section{MEANINGS}

fidelity, faithfulness, dedication,

zeal, allegiance, commitment [notion of loyalty]

love, adoration, affection [notion of love]

worship, prayers, religious rites [religious]

a song by Earth Wind and Fire

a perfume name

CONFUSIONS

MISTAKES

BLANKS

Table 2 (continued)

$85 \quad 67$

369

$22 \quad 5$

$15 \quad 11$

$7 \quad 7$

10

$0 \quad 0$

$0 \quad 0$

22

15

DISASTER $(n=101)$

\section{MEANINGS}

a calamity, annihilation, a catastrophe,

a terrible happening, a cataclysm, a holo-

94

94

caust, a tragedy, a misfortune, a crisis

an emotional disturbance, emotional distress, trauma

a mistake

the failing of an enterprise

CONFUSIONS

MISTAKES

BLANKS

DOUGH $(n=101)$

\section{MEANINGS}

batter, unbaked bread or cookies, a water and flour mixture, stuff that turns into bread when cooked

money, cash

something like dough, clay, a gooey

substance

a doughboy

a name

fat

the color of a pale person

$F \quad F(1 s t)$

\section{CONFUSIONS}

a musical note [confusion with do]

\section{MISTAKES}

[word mistaken as TOUGH]

\section{BLANKS}

\section{MEANINGS}

$$
\text { DROP }(n=101)
$$

to let fall, to let go, to let down a water drop, a piece of rain or water, a rain drop, a tear drop, a bit of liquid, a dribble

to leave off, to quit, to drop a class,

to get rid of a class

fall, slip [unspecified noun or verb]

a small amount

to fall

to get rid of, to dispose of

candy

a measure, an amount

drip [unspecified noun or verb]

to break up a relationship

to forget

eye medicine

a drop off, a cliff

a book drop

licorice in Dutch

a fall

to land

to leave 
Table 2 (continued)

\begin{tabular}{lll}
\hline & F & $F(1 \mathrm{~s})$ \\
\hline & 1 & 0 \\
to go below & 1 & 0 \\
a kind of kick & 1 & 0 \\
something that falls & 1 & 0 \\
a dropcloth & 1 & 0 \\
to drop the subject & 1 & 0 \\
a cookie & 1 & 0 \\
to drop dead & 1 & 0 \\
a difference in height & 1 & 0 \\
decline in performance [unspecified noun & & \\
or verb] & 1 & 0 \\
a lowering & 1 & 0 \\
to write (as in "drop a line") & 1 & 0 \\
the background of a set & 1 & 0 \\
a necklace & 1 & 0 \\
a con man's term & 0 & 0 \\
CONFUSIONS & 0 & 0 \\
MISTAKES & 3 & 3 \\
BLANKS & &
\end{tabular}

\section{MEANINGS}

DYNASTY $(n=96)$

a ruling family, a long lasting rule

[reference to family]

empire, rulers, kingdom [no reference to

family]

sovereignty, regime, power, supremacy

[no reference to family or to government]

an era, the period of a rule, a time period

[a time span]

Ming Dynasty

CONFUSIONS

MISTAKES

BLANKS

\section{MEANINGS}

EMERALD $(n=96)$

a stone, a jewel, a rock, a gem, a green

gem

a color, a green color, green

Emerald City (in The Wizard of $O_{z}$ )

a name, a girl's name

a bay in North Lake Tahoe, Emerald Sea,

Emerald Pool in Yellowstone, a lake in

Canada [a name of an aquatic geographi-

cal feature]

the Emerald Isle, Ireland

a perfume name [Emeraude, French for emerald]

a cutting form for precious stones

CONFUSIONS

MISTAKES

BLANKS

\section{MEANINGS}

EVEN $(n=101)$
Table 2 (continued)

\begin{tabular}{lll}
\hline & $F$ & $F($ lst $)$ \\
\hline
\end{tabular}

the opposite of odd, divisible by 2 ,

2468 . . numbers, multiples of 2

level, balanced, flush

fair

not jagged, straight, smooth

a tied score

also, too, including

to get even, revenge

although, though, except, however

a word indicating more validity, an

intensive, even if, moreover, just as if,

in spite of

to make flat, to make even, to balance

straight

parallel

not in debt

an adverb

still

maybe

square

to make equal

52

35

a name

night

symmetrical

CONFUSIONS

MISTAKES

BLANKS

FAULT $(n=96)$

\section{MEANINGS}

an earthquake area, a crack in the earth, uneven rocks, a fracture, a rock fault, a crevice

a mistake, responsibility, the cause of

wrong doing, a failure, an error,

negligence

blame [unspecified noun or verb]

67

36

a tennis error, a foul, a tennis term

a weakness, a failing, a wrongness, a bad

102

93

91

82

81

80

point, a defect, an undesirable trait, an

imperfection

to blame

a bad spot in material

to err

CONFUSIONS

MISTAKES

BLANKS

FELT $(\mathrm{n}=96)$

\section{MEANINGS}

a material, a fabric

the past tense of feel, have feeled

touched 
Table 2 (continued)

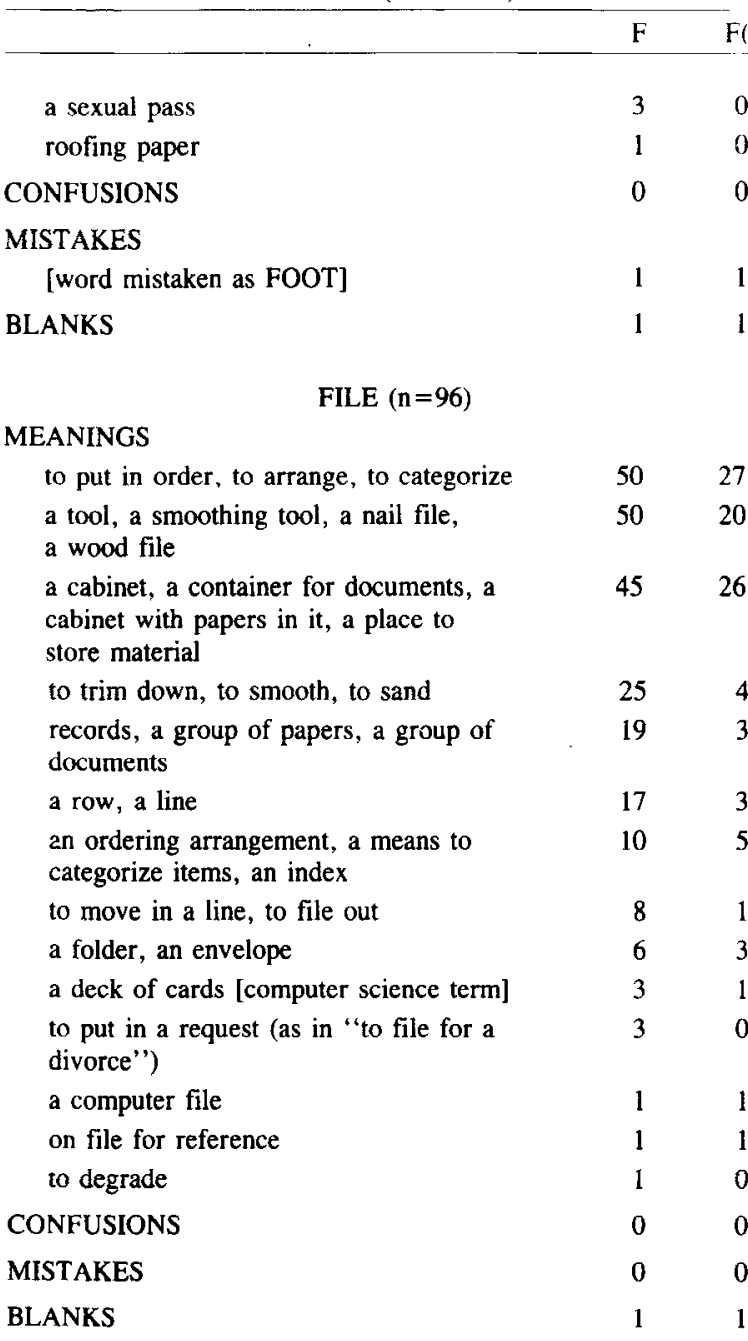

FLOW (n=96)

\section{MEANINGS}

to run smoothly, to glide easily,

to slide smoothly, to run smoothly,

to stream forth [no reference to water]

a rush of liquid, a river's movement,

a movement of liquid, a rush of water,

a stream of water, running water

[reference to water]

to move liquid, to make water run,

to gush water

a river

a movement, a motion

stream, gush, trickle [unspecified noun or verb]

the direction, the direction things are

going, the way motion is going

a continuous motion, continuity

a trend of mind, a state of mind, a mood

a stream

water running [unspecified noun or verb]

a diagram, a chart in computer

programming

the stuff inside ski boots

energy movement, electron flow
Table 2 (continued)

$\mathrm{F} \quad \mathrm{F}(\mathrm{lst})$

a flow of words, a flow of thoughts

that which slides smoothly, a smooth rush

of something

ebb and flow

let it flow, let it go

the rate of streaming, speed

a movement of air

a natural progression

to flair out (as a flowing gown)

the mainstream of something

the movement of sound

the movement of a game

something making good sense

CONFUSIONS

a name [confusion with Flo]

a type of ice [confusion with floe]

MISTAKES

BLANKS

3

3

2

\section{FLUSH $(n=96)$}

MEANINGS

to wash out with a rush of liquid,

to dispose of, to rinse, to get rid of

a poker hand, a card hand, a royal flush

to blush, to turn red, to turn pink,

21

21

$2 \quad 1$

20

11

1

11

10

10

10

to color

a red face, a blush

blush [unspecified noun or verb]

to expel, to cause to come out,

to force out, to scare out, to hunt

immediately adjacent, right next to,

together tightly, true-even

red, pink

pale

to be embarrassed

to be hot

to become pale

a nickname

to look ill

wealthy

to exterminate [slang expression]

to be angered

CONFUSIONS

MISTAKES

BLANKS

$\begin{array}{rr}32 & 12 \\ 18 & 7 \\ 14 & 7 \\ 11 & 7 \\ 11 & 4 \\ & \\ 9 & 2 \\ & \\ 7 & 2 \\ 6 & 2 \\ 5 & 2 \\ 2 & 0 \\ 1 & 1 \\ 1 & 1 \\ 1 & 1 \\ 1 & 0 \\ 1 & 0 \\ 1 & 0 \\ 0 & 0 \\ 0 & 0 \\ 0 & 0\end{array}$

\section{MEANINGS}

FUZZY $(\mathrm{n}=96)$

furry, woolly, fluffy, hairy, soft, linty

not clear, blurry, unfocused, vague

fuzzy-wuzzy the bear, a bear's name

referring to a person's hair

a creature, a toy

a pet's name

$\begin{array}{rr}79 & 58 \\ 44 & 23 \\ 8 & 6 \\ 6 & 2 \\ 4 & 2 \\ 3 & 0\end{array}$

CONFUSIONS

the police [confusion with fuzz]

0
1
1
1
1
0
1
1
1
0
0
0
1
2
0
0


Table 2 (continued)

\begin{tabular}{lll}
\hline & $F$ & $F(1 \mathrm{~s})$ \\
\hline MISTAKES & 0 & 0 \\
BLANKS & 5 & 5
\end{tabular}

GRACE $(n=96)$

\section{MEANINGS}

a girl's name

a prayer, thanks, a prayer before meals

style, charm, poise, elegance, finesse, manners, smoothness [a personality quality]

physical grace, fluidity of movement, balance, not clumsy [a physical quality] the favor of God, God's gift, God's blessing, a state of holiness

mercy, clemency, forgiveness, understanding, lenience, kindness

the period of time allowed for performance of an act or obligation

goodness, decency

a mythological personage

to honor

to enhance or decorate

the title of a religious person

\section{CONFUSIONS}

MISTAKES

BLANKS

HAIL $(n=101)$

\section{MEANINGS}

frozen rain, ice balls, precipitation,

ice, a weather form

to praise, to show respect, to worship,

to honor, to pay homage, to cheer

salutation, greetings

to call out, to cry out

to flag down, to summon, to call a cab

to greet

Southern pronunciation of "hell"

song title

to precipitate hail, to rain ice

a lot of things coming down at once

\section{CONFUSIONS}

Nathan Hail [confusion with Nathan Hale]

hearty [confusion with hale]

\section{MISTAKES}

BLANKS

\section{MEANINGS}

HEEL $(\mathrm{n}=101)$

a part of the foot, the end of a foot

a fool, a bad guy, a jerk, a fink,

an undesirable character, a cad, a scoun-

drel, a creep

a dog following you closely, a dog walk-

ing at your heels, a dog sitting at your

heels, a command to a dog

a part of a shoe, a part of a boot
Table 2 (continued)

$\mathrm{F}$

$\mathrm{F}(1 \mathrm{st})$

the end of a loaf of bread

17

the back part, the base

to walk, to step

a part of the hand

CONFUSIONS

to cure [confusion with heal]

MISTAKES

BLANKS

IDEAL $(n=96)$

\section{MEANINGS}

perfect, preferred, best, just right, best possible, ultimate, utopian

a goal, a standard, something looked up

to, a model, a mental notion of perfection, something strived for, an aspiration

a toy company, a trademark for toys

an idea, a thought, a belief

the name of a market, the name of

supermarkets, a furniture store

a trademark, a brand name

\section{CONFUSIONS}

MISTAKES

BLANKS

\section{MEANINGS}

opposite of out, not out

denoting what's in fashion,

in vogue, hip, with it, fashionable

indoors, inside a house [reference to

entering a house or room]

inside, not outside

within, being in, contained

belonging, accepted by peers

a reference to a location, a certain space

a connection, an "in"

into

the in crowd

present

a reagent in chemistry [suffix]

internal

a prefix

an entrance

an opening
79

38

27

13

9

$$
6
$$

57

10

7

5

0

0

0

0
CONFUSIONS

a hotel [confusion with inn]

\section{MISTAKES}

BLANKS

\section{MEANINGS}

INTEREST $(n=101)$

money accrued, dividends, money compounded on account, the return on money

to fascinate, to care about, to intrigue, to excite, to like, to stimulate, to want to know about

3
0
0
0
0
0
1

7
7
0
7
5
0
0
0
0
0 1 
Table 2 (continued)

\begin{tabular}{lcc}
\hline & $F$ & $F(1 \mathrm{~s})$ \\
& & \\
something you like, something you desire & 26 & 17 \\
to do, an attraction, a like, a liking, what & & \\
you want or desire & 11 & 8 \\
curiosity, attention, wonderment & 8 & 5 \\
a hobby & 7 & 5 \\
interest, concern, like lunspecified noun & & \\
or verb] & 5 & 2 \\
knowledge, a field of study & 1 & 0 \\
financial control & 1 & 0 \\
to make someone aware of & 1 & 0 \\
enthusiasm for & 0 & 0 \\
CONFUSIONS & 0 & 0 \\
MISTAKES & 8 & 8 \\
BLANKS* &
\end{tabular}

*The high number of BLANKS is due to the large number of subjects who listed only associates and no meanings.

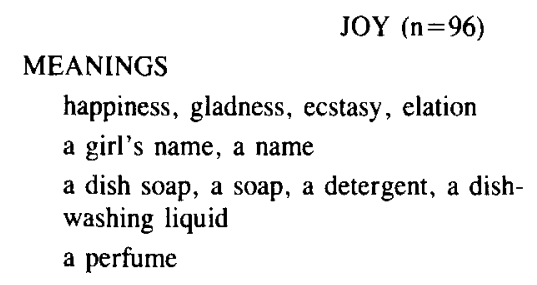

CONFUSIONS

MISTAKES

BLANKS

\section{MEANINGS}

KEY $(n=96)$

an instrument to unlock something, a device to unlock a lock, an object to open a door

a clue, a solution, an explanation, an

answer

the answer sheet for an exam

important

a means of gaining entrance

the tonic part of the scale

a key for deciphering a map

to focus in on something

an index

a drug measure

a geographical term, an inlet

a magazine name

typewriter keys

to key in, to enter

a symbol

decipher code [unspecified noun or verb]

anything like a key

a key club

a part of a basketball court

CONFUSIONS

MISTAKES

BLANKS
Table 2 (continued)

KNOWLEDGE ( $\mathrm{n}=96)$

\section{MEANINGS}

wisdom, understanding, experience,

intelligence [a persona] quality]

what is known, facts, information.

concepts, facts known, truth, certainties,

stored information, what a person knows

[facts that are known]

knowing, to know something,

learning, awareness, cognition,

perception [a cognitive process]

know how, gaining new skills,

common sense lcompetence in

performance]

\section{CONFUSIONS}

MISTAKES

$42 \quad 35$

BLANKS*

115

*The high number of $B L A N K S$ is due to the large number of subjects listing only associates and no meanings.

\section{MEANINGS}

$\operatorname{LEAD}(n=101)$

to lead someone, to guide, to take charge,

$68 \quad 38$

to demonstrate, opposite of to follow,

to show the way

$\begin{array}{lll}\text { a metal, a mineral, an ore } & 56 & 28\end{array}$

$\begin{array}{lll}\text { a pencil lead, pencil graphite } & 37 & 17\end{array}$

$\begin{array}{lll}\text { an element } & 20 & 7\end{array}$

a heavy material, something that is heavy $17 \quad 3$

the front $\quad 8 \quad 3$

a bullet

the head of something, the leader

a protective shield

the starring role, a head role in a play

a weight

a leash or rope

a clue in a mystery

an example (as in "to take my lead")

\section{CONFUSIONS}

MISTAKES

BLANKS

LEGISLATION $(\mathrm{n}=96)$

\section{MEANINGS}

laws, rules, rulings, enforcements, amendments, decrees [decisions made] the creation of laws, the passing of laws, deciding issues, legal decisions, enacting laws, the passage of laws, the making of laws, passing bills [the making of decisions]

bills. matters under consideration, sug gestions of new modes of governing, issues, proposals [decisions to be made]

\section{CONFUSIONS}

a governmental branch, a body of government, a group that writes laws. 
Table 2 (continued)

F $\quad F(1 \mathrm{st})$

a body of rulers, government [confusion with legislature]

MISTAKES

BLANKS

LORD $(n=101)$

MEANINGS

God, Jesus, Krishna, a religious name

a nobleman, nobility, royalty

a king, a ruler

an expression, an exclamation, a curse

word

a master, a superior

a feudal lord, a medieval rank, a

medieval landowner

to rule over

a man of high rank, an important figure,

a person with authority

a title

the keeper of the house in olden times,

the master of the house, the head of the manor

a nickname, a name

a wealthy man

\section{CONFUSIONS}

\section{MISTAKES}

BLANKS

$$
\text { LOYALTY }(n=101)
$$

\section{MEANINGS}

the quality of being loyal, the state of being loyal, devotion, dedication, obedience, faithfulness, allegiance, being true to someone, steadfastness

a tie

\section{CONFUSIONS}

MISTAKES

BLANKS*

*The high number of BLANKS is due to the large number of subjects who listed only associates and no meanings.

\section{MARRIAGE $(\mathrm{n}=96)$}

\section{MEANINGS}

the joining of man and woman, wedlock, matrimony, the legal bond of man and wife, the legal relationship of man and wife, the commitment of man and wife [the joining of persons]

a union, a combination, a joining, a a merger, a bond [the joining of, persons or things not specified]

a wedding, a wedding ceremony, a ceremony

the joining of two things, the unity of something, the joining of two objects, the connection between two things [the joining of things]

a sacrament

the integration of two concepts
Table 2 (continued)

\begin{tabular}{lrc}
\hline & F & F(lst $)$ \\
\hline symbiosis & 1 & 0 \\
$\quad$ the king and queen in pinochle & 1 & 0 \\
CONFUSIONS & 0 & 0 \\
MISTAKES & 0 & 0 \\
BLANKS* & 11 & 11
\end{tabular}

*The high number of BLANKS is due to the large number of subjects who listed only associates and no meanings.

$$
\text { MASS }(n=101)
$$

\section{MEANINGS}

a religious service, a church service, a

ceremony, a Catholic ritual

a weight, the measurement of substance,

a quantity of matter, a physics term

[a quantity of material]

a great deal of, a great number, lots of, abundance, a bunch of, a lot of, a large amount [a quantity; people or material not specified]

a large crowd, a large number of people,

a group of people [a quantity of people]

a group of things, a group of something,

a group of objects

the abbreviation of Massachusetts

to come together

directed towards the body of people (as in mass media)

the people or the workers

mass production

\section{CONFUSIONS}

a part of a ship [confusion with mast]

\section{MISTAKES}

\section{BLANKS}

\section{MEANINGS}

MEMORY $(n=101)$

recall, one's process of recalling, the ability to recall things, the system of storing information, the act of remembering, the part of the mind for remembering [a process or system for remembering] a recollection, something that is remembered, a past event, a reminiscence, past thoughts [what is remembered] remembrance, recollection [unclear whether reference is to what is remembered or to a process]

a part of a computer, a part of a calculator

a brand name

a game

in memory of

CONFUSIONS

103 MISTAKES

BLANKS 
Table 2 (continued)

$\mathrm{F} \quad \mathrm{F}(1 \mathrm{st})$

a machine used to view small objects, a scientific instrument, a magnifier, a high power lens

\section{CONFUSIONS}

very small, precise [confusion with microscopic]

\begin{tabular}{|c|c|c|}
\hline MISTAKES & 0 & \\
\hline BLANKS* & 6 & \\
\hline \multicolumn{3}{|c|}{$\begin{array}{l}\text { *The high number of BLANKS is due to the large number of subj } \\
\text { who listed only associates and no meanings. }\end{array}$} \\
\hline MIGHT $(n=96)$ & & \\
\hline \multicolumn{3}{|l|}{ MEANINGS } \\
\hline strength, power, force & 80 & 59 \\
\hline $\begin{array}{l}\text { maybe, probability, possibility, could } \\
\text { possibly, may, perhaps }\end{array}$ & 76 & 25 \\
\hline CONFUSIONS & 0 & \\
\hline \multicolumn{3}{|l|}{ MISTAKES } \\
\hline [word mistaken as RIGHT] & 4 & \\
\hline [word mistaken as MIDGET] & 1 & \\
\hline BLANKS* & 7 & \\
\hline
\end{tabular}

*The high number of BLANKS is due to the large number of subjects who listed only associates and no meanings.

\section{MEANINGS}

$$
\operatorname{MINE}(n=101)
$$

that which belongs to me, expressing possession or ownership, not yours

a pit for excavating minerals, an excava-

tion site, an ore deposit. a gold mine,

a coal mine

to dig for minerals, to dig

a tunnel, a hole in the ground, a cave

an explosive, a bomb

$\begin{array}{rr}84 & 60 \\ 55 & 16 \\ & \\ 15 & 9 \\ 13 & 5 \\ 9 & 0 \\ & \\ 1 & 0 \\ 0 & 0 \\ 11 & 11\end{array}$

\section{CONFUSIONS}

a German word [confusion with mein]

\section{MISTAKES}

BLANKS*

*The high number of BLANKS is due to the large number of subjects who listed only associates and no meanings.

\section{MEANINGS}

$$
\operatorname{MOLE}(n=101)
$$

an animal, a gopher, a burrowing animal,

a rat, a rodent, a mouselike animal, a small mammal

a pigmentation of the skin, a freckle, a dark spot on the skin, a beauty mark. a

birth mark, a wart

a chemical measure, a gram weight,

Avogadro's number

a hermit, an introverted person

dark (as in "mole dark")

a club

an ugly person

a cartoon character
Table 2 (continued)

$\begin{array}{lrr} & F & F(1 \text { st } \\ \text { a bookworm } & 1 & 0 \\ \text { someone with poor eyesight } & 1 & 0 \\ \text { a type of hole } & 1 & 0 \\ \text { a nickname } & 1 & 0 \\ \text { a person with small eyes } & 1 & 0 \\ \text { someone who likes the dark } & 1 & 0 \\ \text { CONFUSIONS } & 0 & 0 \\ \text { MISTAKES } & & \\ \text { [word mistaken as MOLD] } & 1 & 1 \\ \text { BLANKS* } & 10 & 10\end{array}$

*The high number of BLANKS is due to the large number of subjects who listed only associates and no meanings.

\begin{tabular}{lrr}
\multicolumn{2}{l}{ MOOD $(\mathrm{n}=96)$} & \\
$\begin{array}{l}\text { MEANINGS } \\
\text { a state of mind, emotion, feeling [and }\end{array}$ & 89 & 77 \\
any specified mood] & & \\
atmosphere, tone, setting & 16 & 4 \\
an attitude, a disposition & 12 & 8 \\
a temperament & 7 & 4 \\
a kind of music & 3 & 1 \\
$\quad$ the setting of a story & 2 & 1 \\
$\quad$ a grammatical tense & 1 & 0 \\
CONFUSIONS & 0 & 0 \\
MISTAKES & & \\
$\quad$ [word mistaken as HOOD] & 1 & 1 \\
BLANKS & 0 & 0
\end{tabular}

\section{MEANINGS}

MORAL $(n=101)$

$\begin{array}{lrr}\begin{array}{l}\text { an idea accepted by society, ideas of right } \\ \text { and wrong, values, ideology, standards of } \\ \text { goodness, ethics, principles } \\ \text { ethical, straight, just, decent }\end{array} & 63 & 48 \\ \begin{array}{l}\text { a part of a story, the message of a story } \\ \text { reference to story] }\end{array} & 32 & 19 \\ \begin{array}{l}\text { a lesson to be learned, a meaning, a } \\ \text { message, a lesson, a theme [no reference } \\ \text { to story] }\end{array} & 11 & 6 \\ \text { a name } & & \\ \text { morale } & 5 & 0 \\ \text { sexual inhibitions } & 4 & 4 \\ \text { ONFUSIONS } & 1 & 1 \\ \text { ISTAKES } & 0 & 0 \\ \text { ANKS* } & 0 & 0\end{array}$

*The high number of BLANKS is due to the large number of subjects who listed only associates and no meanings.

\section{MEANINGS}

$$
\text { OLIVE }(n=101)
$$

a food, a black or green food, a vege-

table, a fruit, a black olive, a green olive.

the fruit put in martinis

a color, green, a green color

Popeye's girl friend, a cartoon character

.


Table 2 (continued)

\begin{tabular}{lrc}
\hline & $F$ & $F(1 \mathrm{st})$ \\
\hline a tree & 13 & 3 \\
an oil & 13 & 1 \\
a complexion color & 5 & 0 \\
a branch & 3 & 0 \\
a peace symbol & 2 & 0 \\
a mountain & 1 & 0 \\
a street name & 1 & 0 \\
a city in Europe & 1 & 0 \\
CONFUSIONS & 0 & 0 \\
MISTAKES & 0 & 0 \\
BLANKS* & 10 & 10
\end{tabular}

*The high number of BLANKS is due to this word page not being included in some of the test booklets.

$$
\text { PAGE }(n=101)
$$

\section{MEANINGS}

a book page, the leaves of a book, a piece

of paper in a book, a part of a booklet to be written on or read

a piece of paper, paper to write on

to call, to summon

64

a medieval servant boy, a king's servant, a courtier

a guide, a delivery boy, a messenger, a

Senate messenger

a name, a last name, a first name, a girl's name

to turn pages

a haircut

to mark or number

an event (as a page in history)

an announcement

\section{CONFUSIONS}

\section{MISTAKES}

BLANKS

$$
\text { PALM (n=96) }
$$

\section{MEANINGS}

the hand, the inside of the hand, a part of the hand

a tree

a leaf, a branch, a frond

to steal

to place in the hand, to hold, to use

one's hand, to carry

to conceal in the hand, to hide in the hand

the name of a garden, the name of a

beach, Palm Springs

a basketball violation, holding a basketball

to get rid of

to slap

a name

to beg

to deal cards

to wave

CONFUSIONS
Table 2 (continued)

F

MISTAKES

[word mistaken as PAIN]

BLANKS

\section{PARDON $(n=96)$}

\section{MEANINGS}

to forgive, to exonerate, to release, to

dismiss, to excuse

an apology, sorry, pardon me, excuse me,

excuse one's self

freedom from legal penalties, official

release from guilt, amnesty, what Nixon

got

to free from legal penalties, to let a

criminal off the hook, to grant legal

amnesty

reprieve, forgiveness, dismissal, dismissal $\quad 11$

of guilt

a French word

a name

CONFUSIONS

MISTAKES

BLANKS

\section{MEANINGS}

$$
\text { PASS }(n=101)
$$

to go by something, to move forward,

to go ahead, to go on, to overtake

to not fail, to make the grade, to succeed

on an exam

a mountain traverse, a mountain road,

a road, a mountain crossing

to throw a ball, to throw, to throw something

a sexual advance, a sexual move

a paper indicating the right to travel past a point, a ticket, a passport, a paper giving rights

to hand over, to give to

to play in football, a football throw

to pass up, to forego, to not take, to

skip, to waive, to not accept

to let go by

to ignore, to disregard, to pass over

throw [unspecified noun or verb]

to pass out [may or may not be "to faint"']

to neglect to take a turn

a throw

leave [unspecified noun or verb]

to die

a name

to get through

movement past

to faint

a leave

to show partiality

31
18
15
4
8
7

17

$10 \quad 5$

$8 \quad 1$

$6 \quad 1$

50

31

21

20

11

11

10

10

10

10

10

10

10

$0 \quad 0$ 
Table 2 (continued)

MISTAKES
BLANKS
MEANINGS
love, strong feelings for another person
[attraction to or a feeling for a person]
a strong feeling, an emotion, intensity of
feeling [no reference to attraction or to
a feeling for a person]
physical desire, physical attraction, sexual
attraction, lust [physical or sexual
feelings]
a desire [attraction, no reference to a
feeling for a person]
the name of a plant, a flower
devotion to, involvement with, dedication,
obsession with something
a religious play, an Easter pageant
the name of a fruit, a fruit
an outbreak of anger, hate
the sufferings of Christ
joy
a drink
pink, a color
a goal
a book title
kONFUSIONS
complness, gentleness [confusion with
BLANKS
M

\section{$\mathrm{F}$}

0

1

Filst

I

PENCIL $(n=101)$

\section{MEANINGS}

something to write with, a writing utensil a writing implement, a pen, a writing tool [and any description of a pencil] to mark, to write in, to etch, to write. to sketch in, to write with a pencil pencil-like, thin

\section{CONFUSIONS}

\section{MISTAKES}

BLANKS

PILE $(n=96)$

\section{MEANINGS}

a heap, a group, a lot of, a mound,

a stack, a collection

to heap, to stack, to put on top of, to load heap, group, stack [unspecified noun or verb]

piling, stakes, a beam, a post

a hemorrhoid, acne, a sore

a part of a carpet, the nap

to all jump on, to climb on

to crash, to plow into, to pile into

a nuclear reactor
Table 2 (continued)

fur, a coat lining
a name
CONFUSIONS

$F \quad F(1 s t)$

$\begin{array}{lll}\text { Gomer Pile [confusion with Gomer Pyle] } & 9 & 2 \\ \text { MISTAKES } & 0 & 0 \\ \text { BLANKS } & 4 & 4\end{array}$

\section{MEANINGS}

PLOT $(n=96)$

the theme of a novel, a story theme,

the story line, a movie theme, the main

62

36 action, the meaning

a piece of land, a tract of land

$39 \quad 15$

a grave, a cemetery piece of land,

$31 \quad 14$

a burial ground

an action taken against something, a plan, 31

a conspiracy, an attempt, a scheme, an idea, an evil plan

to connive, to plan, to scheme, to plan 27

against, to devise

to make a map, to note, to mark points,

to put in position on a graph, to graph,

to draw, to set down

plan, scheme [unspecified noun or verb]

a garden patch, a grass patch

graph, chart, sketch [unspecified noun or verb]

a graph or map

to lay out an area

CONFUSIONS

MISTAKES

BLANKS

PRESENT $(\mathrm{n}=96)$

\section{MEANINGS}

a gift

$84 \quad 51$

here. be in attendance, being in a place,

$50 \quad 13$

time now, now, right now, here and now

$42 \quad 17$
42

to give to, to award to

$42 \quad 8$

to show

to introduce, to announce

to give a report, to offer an idea,

to speak on a subject

a tense

existing, being

CONFUSIONS

MISTAKES

BLANKS

RAISE $(n=96)$

\section{MEANINGS}

to elevate, to make higher, to lift

more wages, an increase in salary, a pay

to bring up, to rear children

to increase prices, to increase rent

to leaven. to raise bread

to cultivate, to grow

\section{0}

0

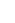

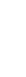

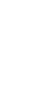

5
4
3
9
3


Table 2 (continued)

\begin{tabular}{|c|c|c|}
\hline & $\mathbf{F}$ & $\mathrm{F}(1 \mathrm{~s}$ \\
\hline to arouse from the dead & 3 & 3 \\
\hline to get up out of bed, to awaken & 3 & 0 \\
\hline to bring up a subject or mention & 1 & 0 \\
\hline to get excited & 1 & 0 \\
\hline to multiply & 1 & 0 \\
\hline \multicolumn{3}{|l|}{ CONFUSIONS } \\
\hline the sun, sunshine [confusion with rays] & 3 & 0 \\
\hline to destroy [confusion with raze] & 2 & 2 \\
\hline MISTAKES & 0 & 0 \\
\hline BLANKS & 1 & 1 \\
\hline \multicolumn{3}{|l|}{ REFINED $(n=96)$} \\
\hline \multicolumn{3}{|l|}{ MEANINGS } \\
\hline $\begin{array}{l}\text { cultivated, well mannered, cultured, } \\
\text { gracious, dignified, sophisticated, } \\
\text { mannerly, genteel, elegant }\end{array}$ & 58 & 36 \\
\hline $\begin{array}{l}\text { made pure, purified, impurities removed, } \\
\text { perfected, improved, made better, cleaned }\end{array}$ & 47 & 35 \\
\hline processed, not in a raw state & 13 & 8 \\
\hline polished, not rough, smoothed & 12 & 5 \\
\hline fined again & 6 & 1 \\
\hline $\begin{array}{l}\text { more detailed, more specific, more } \\
\text { precise, more exact }\end{array}$ & 5 & 4 \\
\hline CONFUSIONS & 0 & 0 \\
\hline MISTAKES & 0 & 0 \\
\hline BLANKS* & 7 & 7 \\
\hline
\end{tabular}

*The high number of BLANKS is due to the large number of subjects who listed only associates and no meanings.

\section{MEANINGS}

$$
\text { ROLL }(n=96)
$$

bread, a bun, a pastry, a biscuit, a

muffin, a croissant, a doughnut

to turn over and over, to make a circular

motion, to spin, to turn, to somersault,

to tumble, to rotate, to flip

a circular motion, a movement

fat, fat around the waist

a money word, a cylinder of coins or bills material rolled up, paper rolled up

a somersault, a movement in gymnastics

a list of names, a roster

to fix a joint, to roll a cigarette

to make something flat, to flatten,

to flatten pie crust

rock and roll music

a drum roll

to rob, to steal from

to push along

a rolling movement (as in throwing dice)

fall [unspecified noun or verb]

to wrap, to fold

to make into a cylinder

to make circular, to make round

to laugh
Table 2 (continued)

\begin{tabular}{lll}
\hline & $F$ & $F(1 \mathrm{~s})$ \\
something round & 1 & 0 \\
a hairdo & 1 & 0 \\
progressing or going well & 1 & 0 \\
a sexual term & 1 & 0 \\
a game & 1 & 0 \\
to roll film & 1 & 0 \\
to crash a car & 1 & 0 \\
CONFUSIONS & & \\
$\quad$ a part in a play [confusion with role] & 2 & 0 \\
MISTAKES & 0 & 0 \\
BLANKS & 1 & 1
\end{tabular}

RULE ( $\mathrm{n}=101)$

\section{MEANINGS}

a law, a policy, a regulation, a code

[a formalized rule]

to govern, to control, to dictate,

to command, to lead

an instrument of measure, a rule, a yard-

stick, something used to measure

something to be followed, something

to obey

a rule of thumb, a guideline, directions,

a standard

to decide, to judge, to make a judgement

how to play a game, directions to a game

a slide rule

the reign of a king

to put lines on, to rule paper

a line

line [unspecified noun or verb]

a theorem

power over others

CONFUSIONS

MISTAKES

BLANKS

SERIES $(n=101)$

\section{MEANINGS}

a sequence, an ordered sequence, an

order, one thing following another, one

after another in sequence, a relationship

in succession, a progression

the world series, baseball games, baseball playoffs, a set of games

a television show, a number of shows

on some topic, soap operas

progressive numbers, numbers, numbers

having a pattern

$\begin{array}{lll}\text { a book series, a magazine series } & 7 & 3\end{array}$

an electrical circuit $\quad 5 \quad 2$

a money series $\quad 2 \quad 0$

CONFUSIONS

MISTAKES

BLANKS 
Table 2 (continued)

\begin{tabular}{|c|c|c|}
\hline & $\mathrm{F}$ & $\mathrm{F}(1 \mathrm{st}$ \\
\hline \multicolumn{3}{|l|}{ SHELL $(n=96)$} \\
\hline MEANINGS & & \\
\hline $\begin{array}{l}\text { the shell of an animal, a sea shell, an } \\
\text { animal covering, the covering of sea } \\
\text { animals, a tortoise shell }\end{array}$ & 77 & 60 \\
\hline $\begin{array}{l}\text { an oil company, a gas company, an oil } \\
\text { trademark, a gas trademark, a gas station }\end{array}$ & 40 & 14 \\
\hline $\begin{array}{l}\text { an encasing, a case, an outer covering, } \\
\text { protection, a protective covering }\end{array}$ & 29 & 14 \\
\hline $\begin{array}{l}\text { to take off the shell, to take off the skin, } \\
\text { to peel, to crack open, to remove the } \\
\text { hard covering from something }\end{array}$ & 8 & 2 \\
\hline to give out, to shell out & 8 & 1 \\
\hline $\begin{array}{l}\text { an impersonal attitude, hiding one's } \\
\text { self, being shy }\end{array}$ & 8 & 0 \\
\hline $\begin{array}{l}\text { ammunition, the casing for ammunition, } \\
\text { a bullet shell }\end{array}$ & 7 & 2 \\
\hline a nut shell, a peanut covering & 7 & 0 \\
\hline egg shell & 5 & 0 \\
\hline to bombard, to bomb & 5 & 0 \\
\hline a blouse, a sweater & 4 & 0 \\
\hline macaroni, a food & 3 & 0 \\
\hline a name, a nickname & 3 & 0 \\
\hline a weapon & 2 & 0 \\
\hline to clean off, to husk & 2 & 0 \\
\hline a camper shell & 2 & 0 \\
\hline a shelter & 2 & 0 \\
\hline $\begin{array}{l}\text { a part of a house, the framework } \\
\text { of a house }\end{array}$ & 2 & 0 \\
\hline an atomic theory & 1 & 1 \\
\hline to $\mathrm{scoop}$ & 1 & 1 \\
\hline a band shell & 1 & 0 \\
\hline a boat & 1 & 0 \\
\hline one's body & 1 & 0 \\
\hline CONFUSIONS & 0 & 0 \\
\hline MISTAKES & 0 & 0 \\
\hline BLANKS & 1 & 1 \\
\hline
\end{tabular}

\section{MEANINGS}

SHOCK $(n=101)$

an electrical shock, voltage, electricity,

a current

medical symptoms, a physiological state,

a medical state, a body condition

surprise [unspecified noun or verb]

a surprise, something unexpected,

an unexpected happening

an emotional state

to scare

surprise, amazement, response to an unexpected event

to surprise, to amaze, to startle

shock absorbers, a part of a car

to electrocute

shock treatment

scare [unspecified noun or verb]

a trauma

113

$10 \quad 5$

$10 \quad 5$

Table 2 (continued)

$\mathrm{F} \quad \mathrm{F}(1 \mathrm{st})$

disbelief

3

fright

to horrify, to appall

a shock of hair

a stimulus

a stun

hurt [unspecified noun or verb]

future shock, culture shock

a scare

to stun

to give hurt to

a tremor, an earthquake

fear [unspecified noun or verb]

extreme fear [noun]

stun [unspecified noun or verb]

shock troops

a shock wave

a bunch of cornstalks

a jolt

CONFUSIONS

MISTAKES

BLANKS

SKIRT $(\mathrm{n}=101)$

\section{MEANINGS}

a dress, clothing, an article worn by a girl, a woman's garment, a half-dress

to go around, to walk around, to go close

to skim around the edges

to avoid, to avoid an issue

the material covering something, the skirt

of a tablecloth, a bed skirt, a Christmas

tree skirt

tank skirts, car skirts, car molding,

machine skirt, an equipment cover

the outside of something, the outer edge $\quad 5 \quad 0$

to move quickly, to jump along, to scoot $3 \quad 2$

along

to border on

outskirts

to wrap around

CONFUSIONS

MISTAKES

BLANKS

$\begin{array}{ll}24 & 5 \\ 16 & 0\end{array}$

\section{MEANINGS}

SLIP $(n=96)$

an undergarment, clothing, lingerie,

a petticoat

to fall, to trip, to stumble, to lose

your footing

a piece of paper

fall [unspecified noun or verb]

to slice

a mistake

3
3
0
0
2
2
1
1
0
0
0
1
1
1


Table 2 (continued)

\begin{tabular}{lll}
\hline & F & F(1st) \\
\hline $\begin{array}{l}\text { to say something inadvertently, to let } \\
\text { out secrets }\end{array}$ & 9 & 1 \\
to make a mistake, to goof & & \\
a clumsy move, a fall, a loss of balance & 5 & 0 \\
something said inadvertently & 5 & 1 \\
to depart secretly, to break off & 5 & 0 \\
a piece of something & 3 & 0 \\
to give to secretly & 3 & 0 \\
to insert & 2 & 0 \\
to do poorly & 2 & 0 \\
a geological feature & 2 & 0 \\
to get by & 1 & 0 \\
to give someone the slip & 1 & 0 \\
a place where you put a boat & 1 & 0 \\
liquid clay & 1 & 0 \\
to put on & 1 & 0 \\
referring to smallness & 1 & 0 \\
a receipt & 1 & 0 \\
an acrobatic movement & 1 & 0 \\
CONFUSIONS & 0 & 0 \\
MISTAKES & 0 & 0 \\
BLANKS & 0 & 0
\end{tabular}

SOUL $(\mathrm{n}=101)$

\section{MEANINGS}

the spirit, the mind, the essence, being,

the inner self, the inner being

soul music, black music, a type of music

black feeling, black awareness, related

to blacks and black culture

soul food, food

depth of feeling

soul brother

a together feeling

rhythm, black rhythm

dancing

the base of something

\section{CONFUSIONS}

a shoe part [confusion with sole]

a type of fish [confusion with sole]

the bottom of the foot [confusion with

sole]

the capital of Korea [confusion with

Seoul]

single [confusion with sole]

MISTAKES

[word mistaken as SOUR]

BLANKS

\section{MEANINGS}

STRAWBERRY $(n=101)$$$
1
$$

Table 2 (continued)

\begin{tabular}{lcc}
\hline & $F$ & $F(1 s)$ \\
& 14 & 0 \\
a burn on the skin, a scrape, a cut, & & \\
a bruise & 5 & 0 \\
a complexion, a haircolor, blond & 4 & 1 \\
a birthmark & 4 & 0 \\
a perfume & 3 & 0 \\
a name & 1 & 1 \\
a plant & 1 & 0 \\
a lipstick & 1 & 0 \\
a record store & 1 & 0 \\
a type of horse-strawberry roan & & \\
CONFUSIONS & 2 & 0 \\
a buzz, an insult [confusion with & & \\
raspberry] & 0 & 0 \\
MISTAKES & 4 & 4
\end{tabular}

\section{MEANINGS}

SWALLOW $(\mathrm{n}=101)$

a bird

to eat, to digest, to chew, to gulp, to

drink, to go through the throat, to ingest gulp, drink [unspecified noun or verb] a gulp, a drink

to be taken in, to believe

to engulf

to accept, to handle

to swallow one's pride

CONFUSIONS

MISTAKES

BLANKS

TAIL $(n=96)$

\section{MEANINGS}

the back part of an animal, a long hairy

appendage, a fifth appendage

the end of something, the back end, the rear end

to follow, to trail, to track

the backside, the ass, the butt

the back of a coin, a side of a coin

a kite tail

the last

the tail gate, the end gate, the end of a truck, the end of a car

a part of a plane

a tuxedo, a suit

a following car

slang for a girl

a tail wind

to taper off

CONFUSIONS

a story [confusion with tale]

\section{MISTAKES}

[word mistaken as TALL]

BLANKS 
Table 2 (continued)

THINNER $(n=101)$

\section{MEANINGS}

not as fat, slimmer, skinnier, not wide. narrow, not fatter

paint thinner, a dilutant, turpentine

not thick, diluted, made less in

consistency

more thin [unclear whether this is "not

fat" or "not thick"]

a name

CONFUSIONS

MISTAKES

BLANKS

THREAD $(n=96)$

\section{MEANINGS}

a thin string, a material to sew with,

a string to sew with, yarn, a filament,

a thin cord, a fiber, a ribbon, a material used with a needle

to pass through a tube, to thread a

needle, to work through a hole

to make one's way through, to wind

through, to wind one's way through, to

move through a crowd

clothes [slang]

a line of connectors, small connectors, a

tiny part of something

the grooves on a screw, a groove in a bolt

to intersperse, to weave through

a small amount

something threadlike or hairlike

to throw a difficult pass in football

extending in time

a small clue

CONFUSIONS

a tire surface [confusion with tread]

MISTAKES

BLANKS

TREE $(n=96)$

\section{MEANINGS}

a plant, a shrub, wood [and any specified kind of tree]

a genealogical chart, family descendents

a shoe tree, a hat rack, a rack [a rack]

to trap in a tree, to chase into a tree

a graph, a diagram

a name

a Biblical reference to the Cross

CONFUSIONS

MISTAKES

BLANKS

F $\quad F(1 s t)$

$\mathrm{F}(1 \mathrm{st})$

Table 2 (continued)

TRUCK $(n=96)$

MEANINGS

$80 \quad 62$

$68 \quad 27$

$15-6$

$5 \quad 2$

21

$0 \quad 0$

$0 \quad 0$

33

80

35

7

113

8

50

50

31

21

20

10

10

21

$0 \quad 0$

11

1

a vehicle, a big vehicle, an automobile,

a car, a pickup [and any specified make

of truck]

to move, to move on, to keep going,

37

to leave

to walk, to walk jauntily, to strut

to move, to carry, to haul an item, to cart

transportation, mode of transportation

a hauling device, a cart

a large person, a strong person

to take care of business, to deal

a part of a skateboard

a truck farm

to have a good time

to dance

a name

to move via a truck

CONFUSIONS

MISTAKES

BLANKS

TRUMPET $(n=101)$

\section{MEANINGS}

an instrument, a musical instrument,

a horn, a cornet, a bugle

an elephant's call, a swan's call

to blast, to blare, to sound off,

to bellow loudly, to make a loud noise

a call, a yell, a noise made

to make an announcement, to pronounce

a kind of swan

a big nose

a device to detect sound, a hearing device

a bugler

the noise that a trumpet makes

to make a big deal about something

a blossom

6

to make a noise like a trumpet

to sing

to use a trumpet

a fish species

224

224

136

82

60

41

30

20

$1 \quad 1$

10

10

10

$0 \quad 0$

$0 \quad 0$

22

\section{CONFUSIONS}

a bridge term [confusion with trump] $\quad 1 \quad 0$

MISTAKES

BLANKS

$0 \quad 0$

$5 \quad 5$

\section{MEANINGS}

UTTER $(\mathrm{n}=96)$

to speak, to whisper, to say suddenly, to mumble, to mention 
Table 2 (continued)

F

$\mathrm{F}(1 \mathrm{st})$

\section{CONFUSIONS}

a part of a cow, a milk bag [confusion with udder]

18

MISTAKES

[word mistaken as OTTER]

BLANKS

VISION $(n=101)$

\section{MEANINGS}

sight, the ability to see, eyesight, perception through the eyes, a sense

a premonition, a sight of the future,

a prophecy, a clairvoyant prediction

seen in the imagination, seen in the mind

a spiritual experience, a spiritual image,

a miracle, a religious experience

a hallucination, an apparition, an illusion

a sight, an image, a perception

insight, understanding

a dream

enlightenment, revelation, truth

something beautiful or astounding to see

\section{CONFUSIONS}

\section{MISTAKES}

\section{BLANKS}

WELL $(n=96)$

\section{MEANINGS}

a water well, a water source, a drinking hole, a deep pit usually for water, a hole in the ground for water, a reservoir for water, a hole where water is found [reference to water]

healthy, feel well, opposite of ill expression, exclamation, oh well, well?, interjection, indicates pause or hesitation fine, good, satisfactory, in a good way something like a well, a wishing well a hole, a hole in the ground a deep hole used to extract a liquid, an oil well [no reference to water]

a container, an inkwell

to build up

a last name

CONFUSIONS

MISTAKES

BLANKS

\section{WINDOW $(n=96)$}

\section{MEANINGS}

an opening, a hole, something to look out of, a hole in the wall [an opening]

glass, a glass panel, a pane, a piece of glass [the glass]

a glass opening, glass to look out of, a hole in the wall covered with glass [an opening with glass]
Table 2 (continued)

\begin{tabular}{lcc}
\hline & $F$ & $F(1 \mathrm{st})$ \\
\hline $\begin{array}{l}\text { the windows of my mind, insight } \\
\text { a lens }\end{array}$ & 5 & 2 \\
$\quad$ an area for entry & 1 & 1 \\
CONFUSIONS & 0 & 0 \\
MISTAKES & & \\
$\quad$ [word mistaken as WIDOW] & 1 & 1 \\
BLANKS* & 6 & 6
\end{tabular}

*The high number of BLANKS is due to the large number of subjects who listed only associates and no meanings.

\section{MEANINGS}

$$
\text { WRAP }(n=101)
$$

to enfold, to cover, to enclose, to envelop, $\quad 49$

to surround, to put a covering around

a scarf, a shawl, a coat, a sweater,

a cloak outside paper, plastic wrap, aluminum

wrap, gift wrap, saran wrap

to cover a package, to cover a gift

to cover with paper, to enclose with

paper

to cover, an outer layer, a covering,

something used to cover

cover [unspecified noun or verb]

a clothing article

to wrap it up, to finish

to wrap someone around a tree

to tackle in football

to put on clothes

leg coverings

to embrace

to be preoccupied in

to conceal

a skirt

to tie up

CONFUSIONS

to hit, to strike [confusion with rap]

to knock [confusion with rap]

talk [unspecified noun or verb] [confusion with rap]

to talk [confusion with rap]

hit [unspecified noun or verb] [confusion with rap]

the blame [confusion with rap]

blame [unspecified noun or verb]

[confusion with rap]

knock [unspecified noun or verb]

[confusion with rap]

to blame [confusion with rap] a court charge [confusion with rap]

a knock [confusion with rap]

a hit [confusion with rap]

a talk [confusion with rap]

\section{8}

2

11

5

$$
5
$$

0

0

I

1

1

1

1

0

0

0

10 


\section{REFERENCES}

BatTiG, W. F. (1964). Single-response free word associations for 300 most frequent four-letter English words. Unpublished manuscript. University of Colorado, Department of Psychology, Boulder.

Battig, W. F., \& Montague, W. E. (1969). Category norms for verbal items in 56 categories: A replication and extension of the Connecticut category norms. Journal of Experimental Psychology Monographs, 80(3, Pt. 2).

BegG, I., \& ClaRK, J. M. (1975). Contextual imagery in meaning and memory. Memory \& Cognition, 3, 117-122.

Benjamin, T. B., \& Watt, N. F. (1969). Psychopathology and semantic interpretation of ambiguous words. Journal of Abnormal Psychology, 74, 706-714.

Carroll, J. B., Davies, P., \& Richman, B. (1971). The American Heritage word frequency book. Boston: Houghton Mifflin.

CARTWRIGHT, D. S. (1977). Concreteness-abstractness of verbal stimuli: Is it a dimension? (Tech. Rep. No. 70). Boulder: University of Colorado, Department of Psychology, Institute for the Study of Intellectual Behavior.

Cartwright, D. S., \& Nickerson, C. A. (1979). An empirical thesaurus: Meaning norms for 90 common words. Modern Language Journal, 63, 442-447.

Cohen, B. H., Bousfield, W. A., \& Whitmarsh, G. A. (1957). Cultural norms for verbal items in 43 categories (Tech. Rep. No. 22). Storrs: University of Connecticut.

Cramer, P. (1968). Mediated priming of polysemous stimuli. Journal of Experimental Psychology, 78, 137-144.

Cramer, P. (1970). A study of homographs. In L. Postman \& G. Keppel (Eds.), Norms of word association. New York: Academic Press.

Friendly, M., Franklin, P. E., Hoffman, D., \& Rubin, D. C. (1982). The Toronto word pool: Norms for imagery, concreteness, orthographic variables, and grammatical usage for 1,080 words. Behavior Research Methods \& Instrumentation, 14, 375-399.

GeIS, M. F., \& WinOGRAD, E. (1974). Norms of semantic encoding variability for fifty homographs. Bulletin of the Psychonomic Society, 3, 429-431.

GilHooly, K. J., \& HAY, D. (1977). Imagery, concreteness, age-ofacquisition, familiarity, and meaningfulness values for 205 five-letter words having single solution anagrams. Behavior Research Methods \& Instrumentation, 9, 12-17.

GilHooly, K. J., \& LoGIE, R. H. (1980a). Age-of-acquisition, imagery, concreteness, familiarity, and ambiguity measures for 1,944 words. Behavior Research Methods \& Instrumentation, 12, 395-427.

GILHOOLY, K. J ., \& LoGIE, R. H. (1980b). Meaning-dependent ratings of imagery, age of acquisition, familiarity, and concreteness for 387 ambiguous words. Behavior Research Methods \& Instrumentation, 12, $428-450$

Goldstein, E., Schmitt, J. C., \& Scheirer, C. J. (1978). Semantic effects in encoding specificity: A levels of processing approach. Memory \& Cognition, 6, 13-19.

Gorman, A. M. (1961). Recognition memory for nouns as a function of abstractness and frequency. Journal of Experimental Psychology, 61, 23-29.

HASHTROUdi, S., \& JoHnson, M. K. (1976). Transfer and forgetting: Interpretive shifts and stimulus reinstatement. Journal of Experimen tal Psychology: Human Learning and Memory, 2, 262-272.

KaUSLER, D. H., \& KamichofF, N. C. (1970). Free recall of homographs and their primary associates. Journal of Verbal Learning and Verbal Behavior, 9, 79-83.

Kausler, D. H., Kollasch, S. F. (1970). Word associations to homographs. Journal of Verbal Learning and Verbal Behavior, 9 , 444-449.

KuČERA, H., \& FRANCIS, W. N. (1967). Computational analysis of present-day American English. Providence, RI: Brown University Press.

LEY, R., \& KarKer, J. (1974). Pronunciability ratings of 319 CVCVC words and paralogs previously assessed for meaningfulness and associative reaction time. Bulletin of the Psychonomic Society, 3 , 421-424.
Light, L. L., \& CARTER-SobELL, L. (1970). Effects of changed semantic context on recognition memory. Journal of Verbal Learning and Verbal Behavior, 9, 1-11.

Locascio, D., \& LeY, R. (1972). Scaled-rated meaningfulness of 319 CVCVC words and paralogs previously assessed for associative reaction time. Journal of Verbal Learning and Verbal Behavior, 11, 243-250

Mueller, J. H., Brown, S. C., \& Kausler, D. H. (1975). Pairedassociate transfer with homograph stimuli. Journal of Experimental Psychology: Human Learning and Memory, 1, 169-172.

Nelson, D. L., MCEvoy, C. L., WAlling, J. R., \& WheELeR, J. W., $J_{R}$. (1980). The University of South Florida homograph norms. Behavior Research Methods \& Instrumentation, 12, 16-37.

Nelson, D. L., Walling, J. R., \& McEvoy, C. L. (1979). Doubts about depth. Journal of Experimental Psychology: Human Learning and Memory, 5, 24-44.

Nickerson, C. A., \& Cartwright, D. S. (1979). An empirical thesaurus: Meaning norms for 90 common words-Complete tables (Tech. Rep. No. 85). Boulder: University of Colorado, Department of Psychology, Institute for the Study of Intellectual Behavior.

Noble, C. E. (1952). An analysis of meaning. Psychological Review, 59, 421-430.

Paivio, A., Yuille, J. C., \& Madigan, S. A. (1968). Concreteness, imagery, and meaningfulness values for 925 nouns. Journal of Experimental Psychology Monographs, 76(1, Pt. 2).

Palermo, D. S., \& JeNKINS, J. J. (1964). Word association norms: Grade school through college. Minneapolis: University of Minnesota Press.

Perfetti, C. A., Lindsey, R., \& Garson, B. (1971). Association and uncertainty: Norms of association to ambiguous words (Report). Pittsburgh, PA: University of Pittsburgh, Learning and Research Development Center.

PosNansky, C. J. (1978). Category norms for verbal items in 25 categories for children grades 2-6. Behavior Research Methods \& Instrumentation, 10, 819-832.

Postman, L., \& KepPeL, G. (Eds.) (1970). Norms of word association. New York: Academic Press.

RowE, E. J. (1973). Frequency judgments and recognition of homonyms. Journal of Verbal Learning and Verbal Behavior, 12, 440-447.

Schyaneveldt, R. W., \& Meyer, D. E. (1973). Retrieval and comparison processes in semantic memory. In S. Kornblum (Ed.), Attention and performance $I V$. New York: Academic Press.

Shapiro, S. I., \& Palermo, D. S. (1970). Conceptual organization and class membership: Normative data for representatives of 100 categories. Psychonomic Monograph Supplements, 3(11, Whole No. 43).

Skanes, G., \& Donderi, D. C. (1973). Stimulus set, response set, and word identification. Journal of Experimental Psychology, 99, 413-423.

SPREEN, O., \& Shultz, R. W. (1966). Parameters of abstraction, meaningfulness, and pronunciability for 329 nouns. Journal of Verbal Learning and Verbal Behavior, 5, 459-468.

Stratton, R. P., Jacobus, K. A., \& Brinely, B. (1975). Age-ofacquisition, imagery, familiarity, and meaningfulness norms for 543 words. Behavior Research Methods \& Instrumentation, 7, 1-6.

THORNDIKE, E. L., \& LORGE, I. (1944). The teacher's word book of 30,000 words. New York: Teachers College Press, Columbia University.

Toglia, M. P., Battig, W. F., Barrow, K., Cartwright, D. S., Posnansky, C. J., Pellegrino, J. W., Moore, T. J., \& Camilli, G. A. (1978). Handbook of semantic word norms. Hillsdale, NJ: Erlbaum.

UyedA, K. M., \& MANDler, G. (1980). Protypicality norms for 28 semantic categories. Behavior Research Methods \& Instrimentation, $12,587-595$.

WALKER, H. J. (1970). Imagery ratings for 338 nouns. Behavior Research Methods \& Instrumentation, 2, 165-167.

WINER, B. J. (1971). Statistical principles in experimental design (2nd ed.). New York: McGraw-Hill

Winograd, E., \& ConN, C. P. (1971). Evidence from recognition memory for specific encoding of unmodified homographs. Journal 
of Verbal Learning and Verbal Behavior, 10, 702-706.

Wollen, K. A., Cox, S. D., Coahran, M. M., \& Shea, D. S. (1979, November). Homograph coding and cerebral laterality. Paper presented at the meeting of the Psychonomic Society, Phoenix, AZ.

Wollen, K. A., Cox, S. D., Coahran, M. M., Shea, D. S., \& Kirby, R. F. (1980). Frequency of occurrence and concreteness ratings of homograph meanings. Behavior Research Methods \& Instrumentation, 12, 8-15.

\section{NOTE}

1. The concreteness ratings of a few words drawn from the Toglia et al. (1978) normative list exceed slightly the limits of the concreteness levels (high, medium, or low) to which they are assigned. This occurs because the concreteness ratings of the words in the present study were not actually drawn from the Toglia et al. (1978) norms, but from an earlier preprint of those norms. The slight discrepancies in concreteness ratings between the two versions of the norms are due to differences in the computational methods used in the two versions.
(Manuscript received March 21, 1984; revision accepted for publication June $21,1984$. 